\title{
Meshing Contact Impact Properties of Circular Arc Tooth Trace Cylindrical Gear Based on Rotating Knife Dish Milling Process
}

\author{
Dengqiu Ma $\mathbb{D}^{1,2}$ Yongping Liu ${ }^{1},{ }^{1}$ Zhenhuan Ye, ${ }^{2}$ Yongqiao Wei, ${ }^{1}$ Dawei Li, ${ }^{1}$ \\ and Xu Zhang ${ }^{2}$ \\ ${ }^{1}$ School of Mechanical and Electrical Engineering, Lanzhou University of Technology, Lanzhou 730000, China \\ ${ }^{2}$ School of Engineering and Technology, Zunyi Normal College, Zunyi 563006, China \\ Correspondence should be addressed to Yongping Liu; cameliu@163.com
}

Received 21 September 2020; Revised 27 November 2020; Accepted 16 December 2020; Published 13 January 2021

Academic Editor: Mohamed Shaat

Copyright (c) 2021 Dengqiu Ma et al. This is an open access article distributed under the Creative Commons Attribution License, which permits unrestricted use, distribution, and reproduction in any medium, provided the original work is properly cited.

Taking the circular arc tooth trace (CATT) cylindrical gear as a research object, in order to obtain the CATT cylindrical gear's meshing contact impact properties, the meshing contact impact hypothesis of the CATT cylindrical gear was put forward based on the contact dynamics theory and gear transmission physical model, and the gear mesh contact impact model was set up further. The finite element solution algorithm for solving the impact problem was given. Then, the accurate 3D model was set up based on the gear tooth surface equation, and the finite element analysis models of the meshing contact impact with different impact positions were established further. The model was to study the distribution rule of the gear surface meshing contact impact stress and relationship between the impact velocity, impact position, and the impact stress. Moreover, the reason for the maximum impact stresses distribution rule of primary and secondary impact tooth surface was discussed. Research result shows the driven wheel dangerous areas of gear root impact are the gear top of the primary impact tooth surface and the gear root of the secondary impact tooth surface; the driven wheel dangerous areas of gear top impact are the gear root of the primary impact tooth surface and gear top of the secondary impact tooth surface; the driven wheel dangerous areas of pitch circle are the gear root and pitch circle of secondary impact tooth surface; and impact velocity and impact position have a major influence on the impact stress. The study results provide a theoretical basis for the dynamic design and industrial application of CATT cylindrical gears.

\section{Introduction}

Many works have been performed by many researchers $[1,2]$. But, the circular arc tooth trace (CATT) cylindrical gear is a new kind of gear transmission. Comparing with an involute spur, the CATT cylindrical gear has the arc tooth line, which has advantages of the bigger contact ratio, heavy load, low sensitivity to installation errors, and no axial force. These factors make it bear bigger loading and more stable under a particular situation [3-5].

Since the curved tooth cylindrical gear was put forward by the Japanese researchers, lots of works about the CATT cylindrical gear have been done by many researchers. The main research content includes meshing principle and 3D modeling, processing method, contact performances, and product development. In terms of meshing principle and 3D modeling, Litvin et al. $[6,7]$ derived the ideal meshing equation of the
CATT cylindrical gear, the profile equation of the conjugate tooth, and the contact line equation by using the gear meshing kinematic method, which laid the theoretical basis of the research. And then, Tseng [8-10], Zhao et al. [11], and Ma et al. [12] studied the meshing principle, deduced the tooth surface equation, and established a 3D model based on the meshing principle further. In terms of processing method, Song et al. [13] and Chang et al. [14], respectively, proposed two processing methods of the CATT cylindrical gear. Namely, parallel connecting rod device milling processing and large cutter head milling processing. But the gear processed by different processing technology is different. The gear tooth profile processed by parallel connecting rod device is involute tooth profile in the whole tooth widths, the gear tooth profile processed by large cutter head milling processing is involute tooth profile in the middle section, and the other sections are the envelopes of the 
hyperbolic curve [12]. However, the actual processing of the CATT cylindrical gear has not been achieved yet. The CATT cylindrical gear generally was processed by using multiaxis CNC machine tools now. In terms of product development, the CATT cylindrical gear has been used in the gear pump [15]. Moreover, the gear CATT cylindrical gear reducer was designed [16]. In terms of contact performances, FuentesAznar et al. [17, 18], Zhang et al. [19], Chen and Lo [20], Sun et al. [5], and Wei et al. [21, 22] have investigated the contact performance of CATT cylindrical gears, mainly including contact strength, thermal elastohydrodynamic lubrication, bending strength, gear transmission errors, computerized design, three-dimensional model, meshing simulation by the finite element analysis, installation error, and the influence of main design parameters on contact performances.

According to the current references, the study of the CATT cylindrical gear is disorderly, and a complete theoretical system has not been established so far. About the contact performances, the current contact characteristics analysis is a basic static analysis, which is a certain position in the gear meshing transmission, and it is not sequential. However, the meshing process of the CATT cylindrical gear is an extremely complex dynamic problem due to the complex structural characteristics, internal excitation, and external excitation. The static analysis cannot effectively reflect the mechanical characteristics of the CATT cylindrical gear, especially the meshing contact impact. It is necessary to investigate the meshing contact shock to reduce the vibration and noise in the CATT cylindrical gear transmission system.

Regarding the gear shocks, scholars pay more attention to two aspects, the first is the impact caused by tooth deformation and machining error, and the second is the impact caused by the gap between teeth. In fact, meshing contact impact will be produced in the gear transmission system, which is caused by the instantaneous normal speed difference of the driving and driven wheels during the meshing process. And it has a great influence on the stability of gear meshing, but there are no meshing contact impact papers about the CATT cylindrical gear transmission. However, the methods used in other gear impact research can be used for a reference. The related literature are reviewed as follows.

For a long time, analytical methods and finite element methods were used to study the dynamic contact characteristics of gears under the impact. For example, He et al. [23] present a novel calculation method for accurately determining the meshing impact of helical gears. Hu et al. [24] established the dynamic model of the meshing impact considering the contact ratio and obtained meshing stiffness of a single tooth by loaded tooth contact analysis and tooth contact analysis to calculate meshing impact force. Guo and Fang [25] proposed a distinctive method to analyze the vibration response of helical gears in the presence of random manufacturing errors and modifications. Munro et al. [26] studied the relationship between outside line meshing and transmission error to derive a quantitative calculation formula. Bajer and Demkowicz [27] used the rigid body contact finite element method to study the dynamic contact impact of the gear system. In short, the finite element method provides convenience for the gear dynamic contact research, and it has the characteristics of high efficiency, high reliability, and high precision of research results. So it is widely used in the research of gear dynamic characteristics $[23,28]$, and it provides a method to investigate the meshing contact impact of CATT cylindrical gear transmission.

During the meshing process of the CATT cylindrical gear, due to the existence of the different normal speeds of the driving and driven gears at the contact point, the meshing contact impact hypothesis of the CATT cylindrical gear was put forward based on the contact dynamics theory and gear transmission physical model. Then, a finite element solution algorithm for solving the impact problem was given. Next, an accurate 3D model was set up to establish the FEA models of the meshing contact impact with different impact positions. Finally, the distribution rule of the gear surface meshing contact impact stress and relationship between the impact velocity, impact position, and the impact stress were investigated. The research results provide a reference for the designing, profile modification, and lubrication of the CATT cylindrical gear.

\section{Meshing Contact Impact Theory}

According to reference [29], Figure 1 is a contact diagrammatic sketch between two elastic bodies; the motion control equation from the start time $t_{A}$ to the end time $t_{E}$ could be presented as follows:

$$
\mathbf{M} \cdot\left(\dot{U}_{E}-\dot{U}_{A}\right)+\lim _{t_{E} \longrightarrow t_{A}} \int_{t_{A}}^{t_{E}}(\mathbf{C} \dot{U}+\mathbf{K U}-\mathbf{F}-\mathbf{R}) \mathrm{d} t=0,
$$

where $\mathbf{M}, \mathbf{C}$, and $\mathbf{K}$ are the mass, damping, and stiffness matrixes of the $\Omega_{1}$ and $\Omega_{2} ; \mathbf{F}$ and $\mathbf{R}$ is the external load and contact force of the $\Omega_{1}$ and $\Omega_{2}$; $\mathbf{U}$ and $\dot{U}$ is the displacement and velocity of the $\Omega_{1}$ and $\Omega_{2}$.

It can be seen from equation (1) that the speed change amount of the system is zero or a small amount after touch when the speeds of the two elastic contact bodies $\Omega_{1}$ and $\Omega_{2}$ are the same or the speed difference between $\Omega_{1}$ and $\Omega_{2}$ is small. That is to say, the contact between the two elastic contact bodies $\Omega_{1}$ and $\Omega_{2}$ usually lasts for a period of time, namely, continuous contact. In contrast to this, when the two elastic contact bodies $\Omega_{1}$ and $\Omega_{2}$ are in contact with a certain relative velocity, there is a stepchange in the system velocity. However, the contact time is very short. During this contact process, the position of the impacted elastomer is generally considered to be bounded, namely, the contact body $\Omega_{1}$ impact the contact body $\Omega_{2}$ with a certain relative velocity, a large contact force will be generated.

Figure 2 can be regarded as the physical model of the CATT cylindrical gear transmission. The gear contact impact can actually be seen as the contact impact produced when two elastic contact bodies are in contact with a certain relative velocity. According to the characteristics of the involute gear, when the gears mesh normally, there is a velocity difference in the tangential direction and no velocity difference (namely, $\Delta v=0$ ) in the normal direction at the gear contact point. That is to say, the transmission is stable and no disengagement meshing phenomenon occurs. However, in reality, there are various factors which make the gear system drive unstably, for example, elastic deformation, load and rotation speed fluctuation, time-varying meshing 


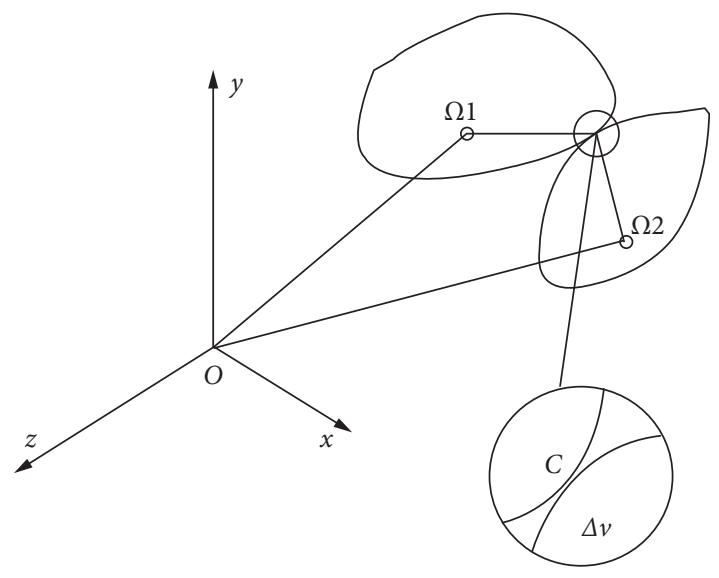

FIGURE 1: Elastic body contact diagrammatic sketch.

stiffness, lubrication state, and time-varying friction. It generates a relative speed difference between the driving wheel and the driven wheel in the normal direction, and the contact form between the gears can be regarded as an impact collision between two elastic bodies. Due to the short period of time, in gear transmission, when the two gear teeth are in contact with a certain relative velocity, multiple slaps will occur between the driving wheel and the driven wheel; it is a meshing contact impact of CATT cylindrical gear transmission.

During this impact, the driving wheel hits the driven wheel at a certain speed, the rotation speed of the driving wheel continuously reduces, and the impact force and the angular displacement of the driving wheel continuously increase. When the speed of the driving wheel decelerates to zero, the driving wheel rebounds at a certain speed due to the reaction force. During the rebound process, the driving wheel speed keeps increasing. If the energy loss is not considered, it can theoretically increase to the initial velocity, but the resultant force of the impact and the angular displacement of the driving wheel continues to decrease until it is zero. This process is a half cycle of meshing contact impact; tooth surface $A$ hits tooth surface $B$. In the other half cycle, tooth surface $D$ hits tooth surface $C$, the impact speed, impact force, and driving wheel angular displacement change trend is the same as the first half cycle. In theory, when gear backlash and energy loss are not considered, the change trend of impact force, impact speed, and driving wheel angular displacement is shown in Figure 3.

The change trends of the resultant impact force and the angular displacement of the driving wheel are approximately parabolic within half a period. Reference [23] also indicates that the time-varying curve of the impact force shows a parabolic periodic change when studying the nonlinear impact of the gear transmission three-dimensional gap. It is consistent with the changing trends of the impact force, impact velocity, and angular displacement. In summary, the meshing contact impact is different from the impact of meshing in and out caused by the gear deformation, installation error, and gear backlash and is also different from the node impact caused by the sudden change of the sliding friction direction near the node. That is to say, it is necessary to carry out relevant research, especially for CATT cylindrical gears.

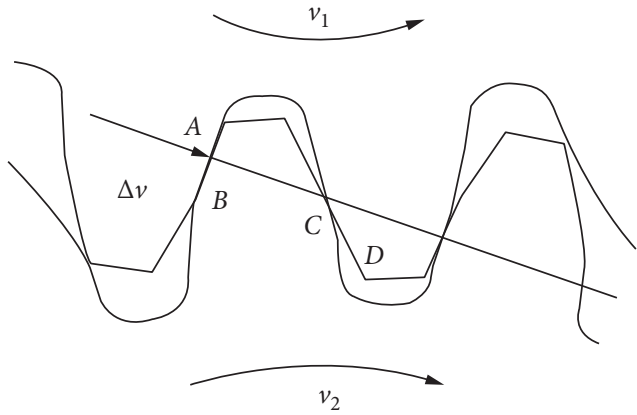

FIgURE 2: Gear transmission physical model.

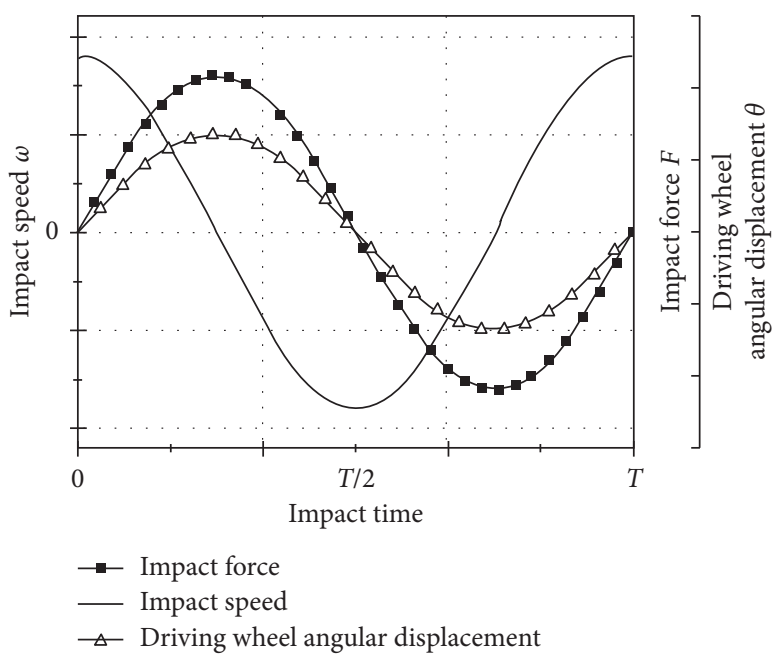

FIGURE 3: Theoretical variation trend of impact speed, impact force, and driving wheel angular displacement.

\section{Finite Element Analysis Methods of Gear Pair Meshing Contact Impact}

3.1. Establishment of Gear Pair System Control Equation. Finite element analysis is an efficient numerical simulation analysis technique, and it provides researchers with great help to solve nonlinear problems in mechanical systems. When solving the meshing contact impact, the entire collision cycle time needs to be discretized as $0, \Delta t, 2 \Delta t, \ldots, t, t+\Delta t, \ldots$, and $T$. Figure 4 is a schematic diagram of the contact at a certain time $t$. In the figure, ${ }^{t} D_{q}$ and ${ }^{t} D_{p}$ are the displacements of driving and driven wheels, respectively; ${ }^{t} S_{q}$ and ${ }^{t} S_{p}$ are the contact surfaces of driving and driven wheels, respectively; the contact section area of the two contact surfaces is ${ }^{t} S_{c}$ (the shape of contact area is an ellipse); ${ }^{t} \mathbf{F}_{l}^{g}$ and ${ }^{t} \mathbf{F}_{l}^{p}$ are the external load vectors that act on the contact area of the driving and driven gear. To easily describe the movement and mechanical state of the gear, respectively, the origin of the rotation center of the driving and driven gear, the rotation centers of the driving and driven gear are set as the origin, respectively, and the rotary axis is set as $z$ axis to establish the coordinate system $O_{g}-x_{g} y_{g} z_{g}$ and $O_{p}-x_{p} y_{p} z_{p}$. A local coordinate system $O^{\prime}-x^{\prime} y^{\prime} z^{q}$ is established at the center of the tooth contact ellipse, the unit vectors in each direction are ${ }^{t} e_{1},{ }^{t} e_{2}$ and ${ }^{t} e_{3}$, respectively, ${ }^{t} e_{1}$ and ${ }^{t} e_{2}$ are located in the common tangent plane of the contact 


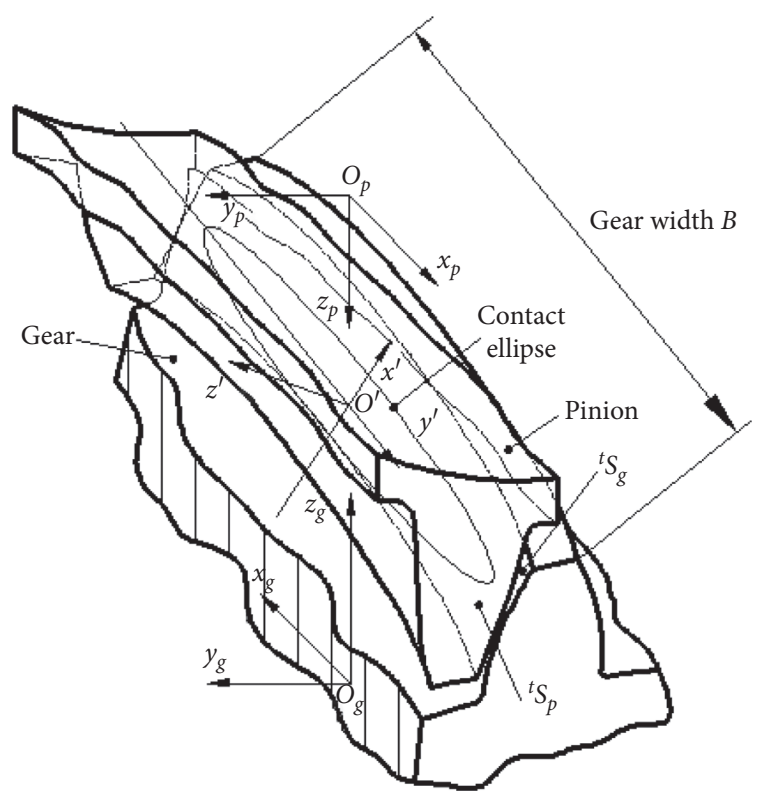

FIgUre 4: Dynamic contact model of CATT cylindrical gear.

ellipse center, and ${ }^{t} e_{3}$ is located on the direction of the common normal line, namely, it is perpendicular to the common tangent plane. ${ }^{t} \mathbf{F}_{c}^{g}$ and ${ }^{t} \mathbf{F}_{c}^{p}$ are the contact force vectors on driving and driven wheel, the direction is the same as the ${ }^{t} e_{3}$.

According to the principle of virtual position, the motion equation of the driving and driven gear expressed in incremental form can be represented as follows:

$$
\left\{\begin{array}{l}
\mathbf{M}_{g}{ }^{t+\Delta t} \ddot{u}_{g}+\mathbf{C}_{g}{ }^{t+\Delta t} \dot{u}_{g}+{ }_{t}^{t} \mathbf{K}_{g} \mathbf{u}_{g}={ }^{t+\Delta t} \mathbf{F}_{l}^{g}+{ }^{t+\Delta t} \mathbf{F}_{c}^{g}-{ }_{t}^{t} \mathbf{F}^{g}, \\
\mathbf{M}_{p}{ }^{t+\Delta t} \ddot{u}_{p}+\mathbf{C}_{p}{ }^{t+\Delta t} \dot{u}_{p}+{ }_{t}^{t} \mathbf{K}_{p} \mathbf{u}_{p}={ }^{t+\Delta t} \mathbf{F}_{l}^{p}+{ }^{t+\Delta t} \mathbf{F}_{c}^{p}-{ }_{t}^{t} \mathbf{F}^{p}
\end{array}\right.
$$

where

$$
\begin{aligned}
& { }^{t+\Delta t} \mathbf{u}_{g}=\left[\begin{array}{c}
{ }^{t+\Delta t} \mathbf{x}_{g} \\
{ }^{t+\Delta t} \mathbf{y}_{g} \\
{ }^{t+\Delta t} \mathbf{z}_{g}
\end{array}\right]-\left[\begin{array}{c}
{ }^{0} \mathbf{x}_{g} \\
{ }^{0} \mathbf{y}_{g} \\
0 \\
{ }^{0} \mathbf{z}_{g}
\end{array}\right], \\
& { }^{t} \mathbf{u}_{g}=\left[\begin{array}{c}
{ }^{t} \mathbf{x}_{g} \\
{ }^{t} \mathbf{y}_{g} \\
{ }^{t} \mathbf{z}_{g}
\end{array}\right]-\left[\begin{array}{c}
{ }^{0} \mathbf{x}_{g} \\
{ }^{0} \mathbf{y}_{g} \\
0 \mathbf{z}_{g}
\end{array}\right] \text {, } \\
& { }^{t+\Delta t} \mathbf{u}_{p}=\left[\begin{array}{c}
{ }^{t+\Delta t} \mathbf{x}_{p} \\
{ }^{t+\Delta t} \mathbf{y}_{p} \\
{ }^{t+\Delta t} \mathbf{z}_{p}
\end{array}\right]-\left[\begin{array}{c}
{ }^{2} \mathbf{x}_{p} \\
0 \\
{ }^{0} \mathbf{y}_{p} \\
0 \\
{ }^{0} \mathbf{z}_{p}
\end{array}\right], \\
& { }^{t} \mathbf{u}_{p}=\left[\begin{array}{c}
{ }^{t} \mathbf{x}_{p} \\
{ }^{t} \mathbf{y}_{p} \\
{ }^{t} \mathbf{z}_{p}
\end{array}\right]-\left[\begin{array}{c}
{ }^{0} \mathbf{x}_{p} \\
{ }^{0} \mathbf{y}_{p} \\
{ }^{0} \mathbf{z}_{p}
\end{array}\right] \text {. }
\end{aligned}
$$

$\mathbf{u}_{g}={ }^{t+\Delta t} \mathbf{u}_{g}-{ }^{t} \mathbf{u}_{g} ; \mathbf{u}_{p}={ }^{t+\Delta t} \mathbf{u}_{p}-{ }^{t} \mathbf{u}_{p} ; \mathbf{M}_{g}$ and $\mathbf{M}_{p}$ are the mass matrixes of the driving and driven wheel, respectively; $\mathbf{C}_{g}$ and $\mathbf{C}_{p}$ are the damping matrixes of the driving and driven wheel, respectively; ${ }_{t}^{t} \mathbf{K}_{q}$ and ${ }_{t}^{t} \mathbf{K}_{p}$ are stiffness matrixes of the driving and driven wheel at the reference moment, respectively; $\ddot{u}_{g}$ and $\ddot{u}_{p}$ are the acceleration of the driving and driven wheel, respectively; $\dot{u}_{g}$ and $\dot{u}_{p}$ are the velocity of the driving and driven wheel, respectively; $\mathbf{u}_{g}$ and $\mathbf{u}_{p}$ are the displacement of the driving and driven wheel, respectively; $\mathbf{F}^{g}$ and $\mathbf{F}^{p}$ are the internal force vector of the driving and driven wheel, respectively.

Motion equation (2) can be rewritten as

$$
\mathbf{M}^{t+\Delta t} \ddot{u}+\mathbf{C}^{t+\Delta t} \dot{u}+{ }_{t}^{t} \mathbf{K u}={ }^{t+\Delta t} \mathbf{F}_{l}+{ }^{t+\Delta t} \mathbf{F}_{c}-{ }_{t}^{t} \mathbf{F},
$$

where

$$
\begin{aligned}
& \mathbf{M}=\left[\begin{array}{cc}
\mathbf{M}_{g} & 0 \\
0 & \mathbf{M}_{p}
\end{array}\right] \text {, } \\
& \mathbf{C}=\left[\begin{array}{cc}
\mathbf{C}_{g} & 0 \\
0 & \mathbf{C}_{p}
\end{array}\right] \text {, } \\
& { }_{t}^{t} \mathbf{K}=\left[\begin{array}{cc}
{ }_{t}^{t} \mathbf{K}_{g} & 0 \\
0 & { }_{t}^{t} \mathbf{K}_{p}
\end{array}\right] \text {, } \\
& { }^{t+\Delta t} \ddot{u}=\left[\begin{array}{ccc}
{ }^{t+\Delta t} \ddot{u}_{g} & \\
& & \\
{ }^{t+\Delta t} & \ddot{u}_{p}
\end{array}\right], \\
& { }^{t+\Delta t} \dot{u}=\left[\begin{array}{c}
{ }^{t+\Delta t} \dot{u}_{g} \\
{ }^{t+\Delta t} \dot{u}_{p}
\end{array}\right], \\
& { }^{t} \mathbf{u}=\left[\begin{array}{l}
{ }^{t} \dot{u}_{g} \\
{ }^{t} \dot{u}_{p}
\end{array}\right], \\
& { }^{t+\Delta t} \mathbf{F}_{l}=\left[\begin{array}{c}
{ }^{t+\Delta t} \mathbf{F}_{l}^{g} \\
{ }^{t+\Delta t} \\
{ }^{g} \mathbf{F}_{l}^{p}
\end{array}\right], \\
& { }^{t+\Delta t} \mathbf{F}_{c}=\left[\begin{array}{c}
{ }^{t+\Delta t} \mathbf{F}_{c}^{g} \\
{ }^{t+\Delta t} \mathbf{F}_{c}^{p}
\end{array}\right], \\
& { }_{t}^{t} \mathbf{F}_{l}=\left[\begin{array}{l}
{ }_{t}^{t} \mathbf{F}^{g} \\
{ }_{t}^{t} \mathbf{F}^{p}
\end{array}\right] .
\end{aligned}
$$


According to the penalty function method [30], the equivalent contact force of the element nodes during the meshing process ${ }^{t+\Delta t} \mathbf{F}_{c}$ can be represented as

$$
{ }^{t+\Delta t} \mathbf{F}_{c}=-a \mathbf{N}_{c}^{T}\left(-\mu \frac{\bar{u}_{1}{ }^{t+\Delta t}}{\bar{u}_{T}} e_{1}-\mu \frac{\bar{u}_{1}{ }^{t+\Delta t}}{\bar{u}_{T}} e_{2}+{ }^{t+\Delta t} e_{3}\right)\left({ }^{t+\Delta t} e_{3} \mathbf{N}_{c} \mathbf{u}_{c}+{ }^{t} \bar{g}_{3}\right)=\mathbf{F}_{T 1}+\mathbf{F}_{T 2}+\mathbf{F}_{3},
$$

where $a$ is the penalty function parameter; $\mathbf{N}_{c}$ is the node interpolation function; $\mu$ is the friction coefficient; $\bar{u}_{T}$ is the tangential displacement increment per unit time of the contact point at time $t ; \bar{u}_{1}$ and $\bar{u}_{2}$ are the two tangential components; ${ }^{t} \bar{g}_{3}$ is the normal distance of the contact point at time $t ; \mathbf{u}_{c}$ is the relative normal displacement; $\mathbf{F}_{T 1}, \mathbf{F}_{T 2}$, and $\mathbf{F}_{3}$ are the equivalent contact force of the tangential and normal component; if friction is not considered, $\mathbf{F}_{T 1}=\mathbf{F}_{T 2}=0$.

3.2. Control Equation Solving of the Gear Pair System. Equation (6) is brought into equation (4) to solve the relevant mechanical parameters. The central difference method is used in the solution and the motion parameters before and after the iteration satisfy the equation as follows:

$$
\left\{\begin{array}{l}
{ }^{t+\Delta t} \mathbf{u}={ }^{t} \mathbf{u}+{ }^{t} \dot{u} \Delta t+0.5 t^{t} \ddot{u} \Delta t^{2}, \\
{ }^{t+\Delta t} \dot{u}={ }^{t} \dot{u}+0.5\left({ }^{t} \ddot{u}+{ }^{t+\Delta t} \ddot{u}\right) \Delta t .
\end{array}\right.
$$

Equation (8) is brought into equation (6) to get the recursive solution formula as follows:

$$
{ }^{t+\Delta t} \mathbf{u}=M+0.5 \Delta t C^{-1}\left[{ }^{t+\Delta t} \mathbf{F}_{l}+{ }^{t+\Delta t} \mathbf{F}_{c}-{ }_{t+\Delta t}^{t+\Delta t} \mathbf{F}-{ }^{t} \dot{u}+0.5 t^{t} \ddot{u} \Delta t \mathbf{C}\right] .
$$
as

The internal force vector ${ }_{t+\Delta t}^{t+\Delta t} \mathbf{F}$ at the $t+\Delta t$ can be written

$$
{ }_{t+\Delta t}^{t+\Delta t} \mathbf{F}={ }_{t}^{t} \mathbf{F}+{ }_{t}^{t} \mathbf{K u}=\sum_{e} \int_{V}{ }_{V}^{t+\Delta t}{ }^{t+\Delta t} \mathbf{B}_{l}^{T}{ }^{t+\Delta t} \widehat{\tau} \mathrm{d} V,
$$

where ${ }_{t+\Delta t}^{t+\Delta t} \mathbf{B}_{l}^{T}$ is the strain and displacement conversion matrix; ${ }^{t+\Delta t} \widehat{\tau}$ is the stress vector.

Combining equations (4)-(9), the various mechanical variables in the entire meshing process of the CATT cylindrical gears can be solved through repeated step-by-step iteration; the finite element analysis flow of the CATT cylindrical gear pairs is shown in Figure 5.

In addition, since the central difference method is a conditional convergence algorithm, the time increment needs to meet the following conditions when the collision period is discrete:

$$
\Delta t \leq \Delta t_{\mathrm{cr}}=\frac{T_{n}}{\pi}
$$

where $\Delta t_{\mathrm{cr}}$ is the critical time step; $T_{n}$ is the minimum natural vibration period.

Research shows that the finite element analysis software has features such as high efficiency, accurate calculation results, and suitable for complex problems. Therefore, in this paper, the algorithm numeral calculation was completed by finite element software ANSYS/LS DYNA.

\section{Results and Analysis of Meshing Contact Shock Solution}

4.1. Finite Element Model of CATT Cylindrical Gears. In order to accurately study the meshing contact impact of the CATT cylindrical gears, it is necessary to establish an accurate 3D model. At present, there are several model methods for this gear [16], but none of them is accurate enough. In reference [12], according to the processing principle of the rotating knife dish milling, using the space meshing theory and differential geometry, the tooth surface equation and the tooth profile of the CATT cylindrical gears have been deduced. The tooth surface equation was represented as follows:

$$
\left\{\begin{array}{l}
x_{1}=\left[-\left( \pm u \sin \alpha+R_{T} \pm \frac{\pi m}{4}\right) \cos \theta+R_{T}+R_{1} \varphi_{1}\right] \cos \varphi_{1}-\left(R_{1}+u \cos \alpha\right) \sin \varphi_{1} \\
y_{1}=\left[-\left( \pm u \sin \alpha+R_{T} \pm \frac{\pi m}{4}\right) \cos \theta+R_{T}+R_{1} \varphi_{1}\right] \sin \varphi_{1}+\left(R_{1}+u \cos \alpha\right) \cos \varphi_{1} \\
z_{1}=-\left( \pm u \sin \alpha+R_{T} \pm \frac{\pi m}{4}\right) \sin \theta \\
u=\mp \frac{\sin \alpha}{\cos \theta}\left[\cos \theta\left(R_{T} \pm \frac{\pi m}{4}\right)-\left(R_{T}+R_{1} \varphi_{1}\right)\right]
\end{array}\right.
$$




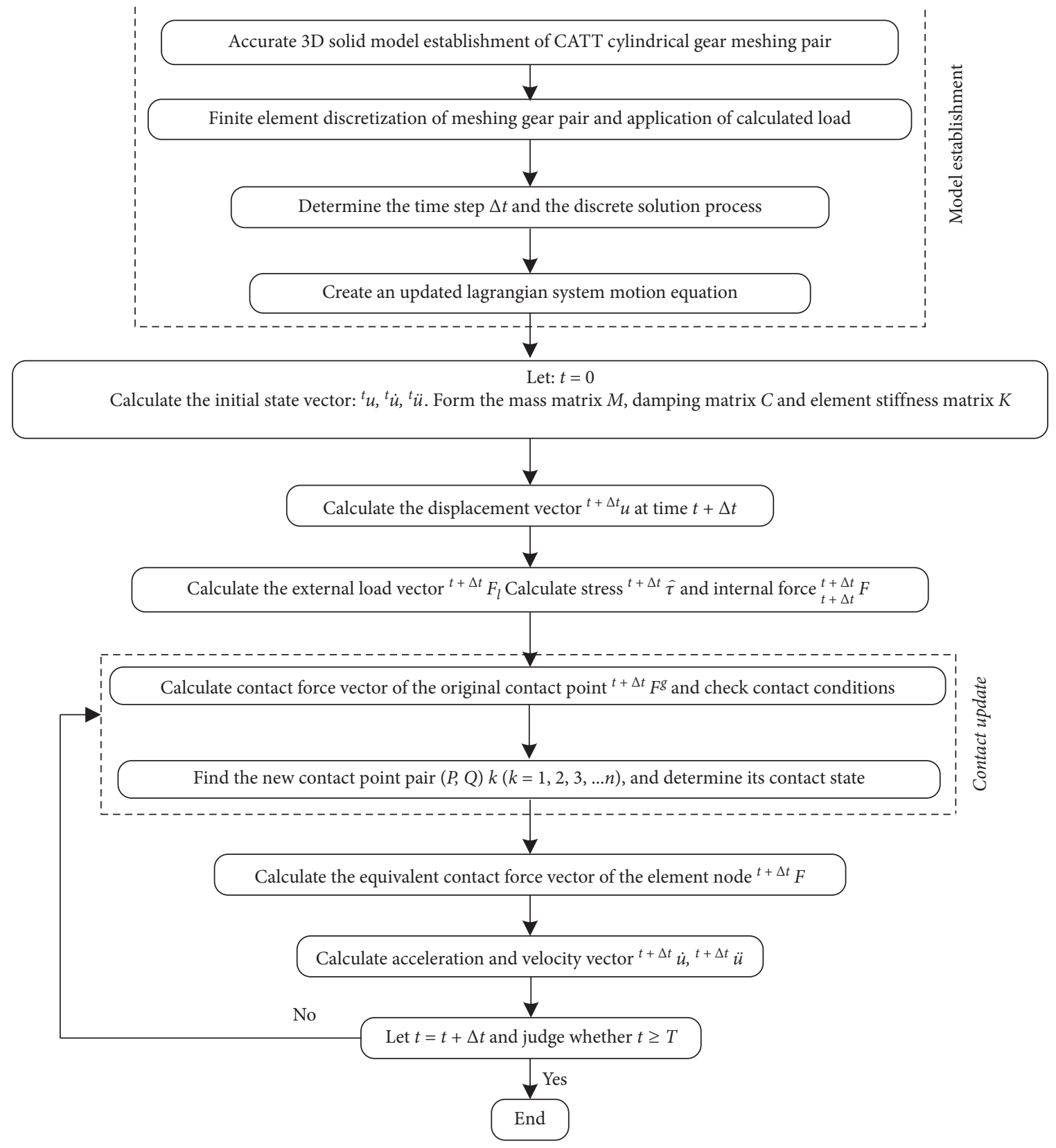

FIgURE 5: Finite element analysis flow of the CATT cylindrical gear pairs.

where $R_{1}$ is the pitch circle of the gear blank; $u$ is the displacement of a point from the blade to the reference point; $\alpha$ (pressure angle) is an angle between the internal and the external cutting edge, the cutter axis, and the knife dish axis. $m$ is the gear modulus; $\varphi_{1}$ is the rotation angle of the gear blank; $R_{T}$ is the cutter radius (tooth line radius); and $\theta$ is the rotation angle measured from the cutter to the end face of the gear blank in the process of machining and called tooth profile position angle, and the clockwise direction is positive.

In this paper, according to the tooth surface equation of the CATT cylindrical gears, MATLAB was used to establish a mathematical model to obtain the tooth surface point cloud, and then, the point cloud of the tooth surface was output and input into UG NX 10.0 to create gear surface. Applying corresponding commands, an accurate 3D model is created and assembled. The parameters of the CATT gears are as follows: $m=8 ; z_{1}=19$ and $z_{2}=31 ; R_{\mathrm{T}}=500 \mathrm{~mm} ; b=80 \mathrm{~mm}$. Figures 6-8 are the single tooth surface model, tooth surface model, and assembled model, respectively.

In order to obtain accurate results and avoid the influence of adjacent gear teeth, the driven gear retains only one gear tooth. And by adjusting the constraint relationship of the three dimensional assembled model, the assembly models which contact near the pitch circle, the tooth root, and the tooth top was established. And then, the assembly model was imported into ANSYS/LS DYNA. The application of the finite element method requires the development of finite element models which are formed of a finite element 
mesh, the definition of contacting surfaces, and the establishment of boundary conditions and velocity of the driving gear with a desired velocity difference. The important parameters and the boundary conditions are set as follows: medium carbon steel (AISI 1045) was selected for the material in the FEA model and Young's modulus and Poisson's ratio of this material are $210 \mathrm{GPa}$ and 0.29 , respectively. The sliding friction coefficient of the contacting surfaces is equal to 0.1, and the static friction coefficient of the contacting surfaces is equal to 0.2 [31]. All freedom degrees of the driven wheel were fully bound, the driving wheel only retained the rotation freedom degree of $z$ axis, and the rest freedom degrees were bound. The velocity difference $\Delta v$ (respectively, $10 \mathrm{rad} / \mathrm{s}, 13 \mathrm{rad} / \mathrm{s}, 16 \mathrm{rad} / \mathrm{s}$, and $20 \mathrm{rad} / \mathrm{s}$ ) is applied to the driving wheel during simulation. Figure 9 is the CATT cylindrical gear's finite element analysis model of meshing contact impact at the different impact positions. The elements and nodes in the FEA model are equal to 35600 and 40600 , respectively.

\subsection{Form Verification of Meshing Contact Impact Collision} Motion. Figure 10 is the change trend of impact velocity, impact force, and angular displacement under a simulation condition. In the first half cycle of meshing contact impact, the change trends of the impact force and the angular displacement of the driving wheel are approximately parabolic. It is obvious that the rotation speed of the driving wheel continuously reduces until it is equal to zero, and then, the driving wheel rebounds because of the reaction force. Moreover, the impact force and the angular displacement of the driving wheel continuously increase. During the rebound process, the resultant force of the impact and the angular displacement of the driving wheel continue to decrease until it is zero, and the driving velocity speed keeps increasing. In the figure, the impact velocity does not increase to the initial velocity, the reason is that the meshing contact impact simulation is a collision between two flexible bodies, and there is certain damping, that is to say, there is an energy loss. As a whole, the change trend of impact velocity, impact force, and angular displacement is consistent with the theoretical analysis in Figure 3 during the entire collision of the gears.

\section{Impact Stress Distribution on Tooth Surface during Meshing Contact Impact}

5.1. Impact Stress Distribution on Tooth Surface of Gear Root Impact. Generally, the gear tooth could be regarded as a cantilever beam with a certain width because of the high rigidity of the gear rim. The stress is generally concentrated at the meshing impact contact section and both sides of the tooth root. The impact contact section is contact stress, and both sides of the tooth root are bending stress. And the concentration sections of the stress are also where the teeth are prone to lose efficacy.

Figure 11 is the impact stresses distribution law of gear top, pitch circle, and gear root while the impact occurs at the gear

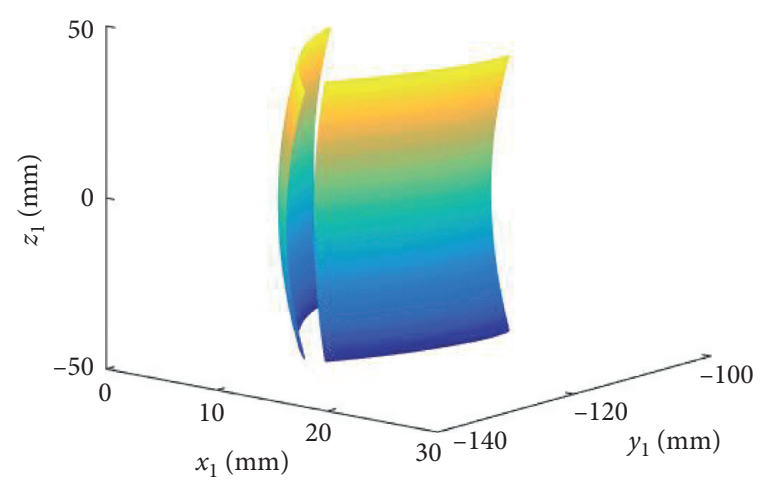

Figure 6: Single tooth surface model.

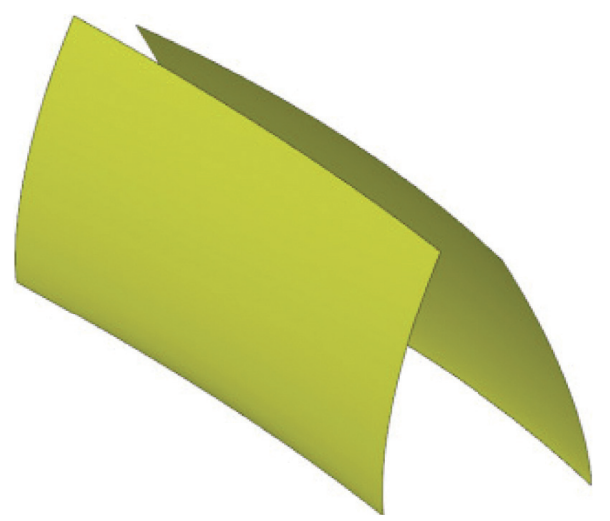

FIgURE 7: Tooth surface model.

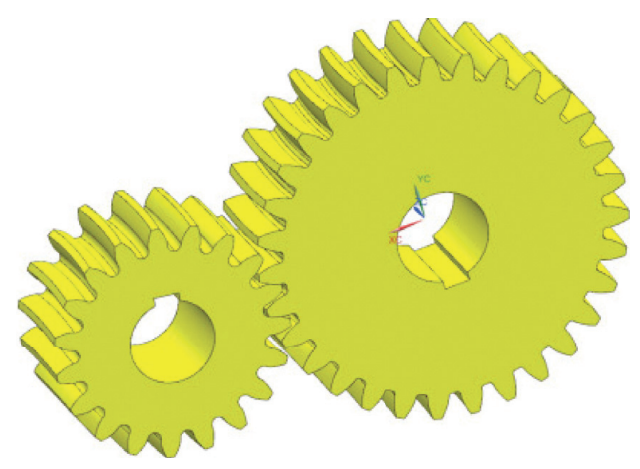

Figure 8: Assembled model.

root (namely, the driving wheel hits the driven wheel at a certain speed while the CATT cylindrical gears' driving gear root, and the driven gear top are in contact. During the rebound process, the driving gear top hits the driven gear root and the velocity difference $\Delta v$ is equal to $20 \mathrm{rad} / \mathrm{s}$ ). I is the impact stress of the primary impact tooth surface and II is the impact stress of the secondary impact tooth surface. The first crest of the impact stress is caused by the primary impact; the second crest of the impact stress is caused by the secondary impact.

According to the curve shown in Figure 11, for the primary impact, the maximum impact stress appears at the gear top of the primary impact tooth surface; it is equal to $350.88 \mathrm{MPa}$. The pitch circle and gear root maximum impact 


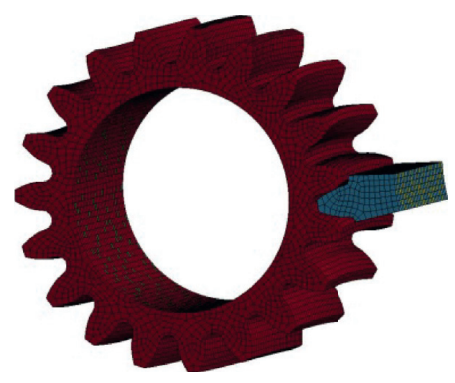

(a)

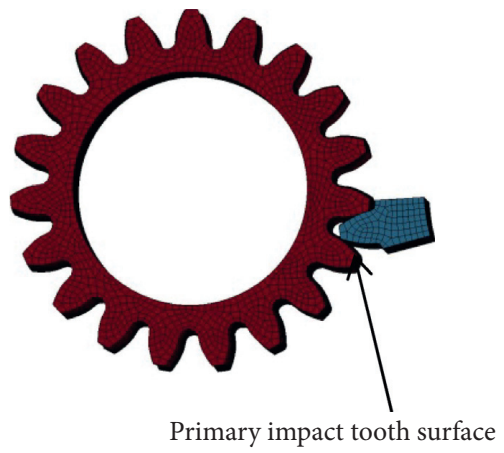

(b)

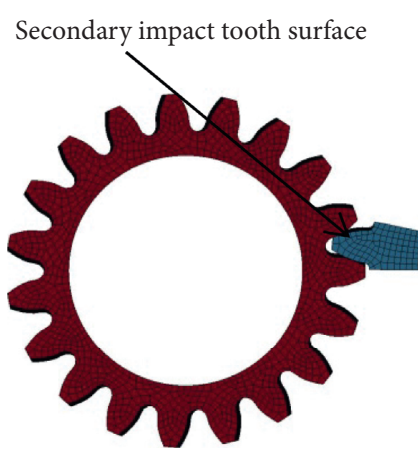

(c)

Figure 9: Meshing contact impact FEA model in different impact positions. (a) Pitch circle meshing contact. (b) Gear root meshing contact. (c) Gear top meshing contact.

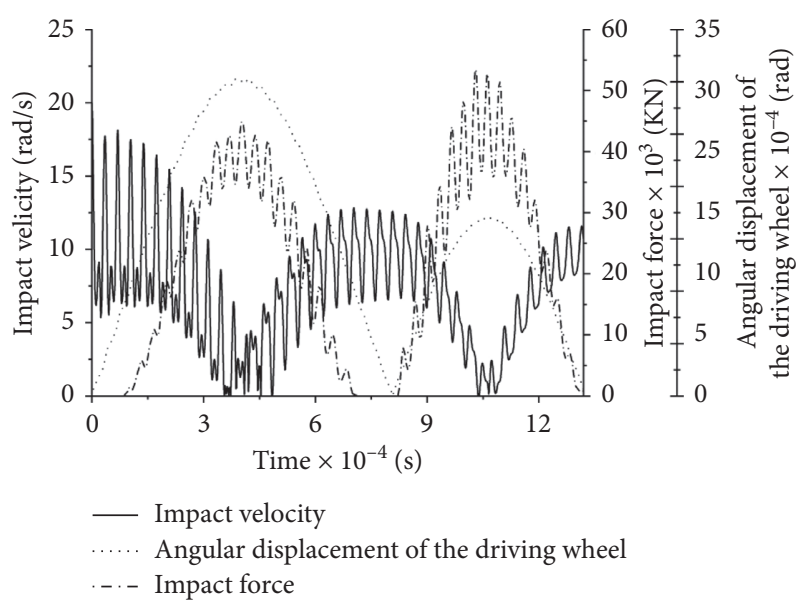

Figure 10: Change trend of impact velocity, impact force, and angular displacement under a simulation condition.

stresses of the primary impact tooth surface are equal to 107.32 $\mathrm{MPa}$ and $123.87 \mathrm{MPa}$, respectively. It indicates that the impact stress of the primary impact tooth surface decreases first and then increases from the gear top to the gear root, but the impact stress near the pitch circle is not much different from the gear root impact stress. Moreover, the gear top, pitch circle, and gear root maximum impact stresses of the secondary impact tooth surface are equal to 80.05 $\mathrm{MPa}, 178.23 \mathrm{MPa}$, and $182.55 \mathrm{MPa}$, respectively. It indicates that the impact stress of the secondary impact tooth surface increases from the gear top to the gear root. On the direction of the gear width, whether it is the primary impact tooth surface or the secondary impact tooth surface, the maximum impact stresses of the gear top, pitch circle, and gear root appear at the middle of gear width. In summary, comparing the impact stress of the primary impact tooth surface and the secondary impact tooth surface, the dangerous areas of the driven wheel appear near the gear top of the primary impact tooth surface and the gear root of the secondary impact tooth surface for the primary impact of the gear root impact.

For the secondary impact of the gear root impact, that is to say, the driving gear top hits the driven gear root. The gear top, pitch circle, and gear root maximum impact stresses of the primary impact tooth surface are equal to $23.95 \mathrm{MPa}$, 29.14 MPa, and 75.30 MPa, respectively. It indicates that the impact stress of the secondary impact tooth surface increases from the gear top to the gear root. Moreover, the gear top, pitch circle and gear root maximum impact stresses of the secondary impact tooth surface are equal to $16.14 \mathrm{MPa}$, 29.42 $\mathrm{MPa}$, and $85.82 \mathrm{MPa}$, respectively. It also indicates that the impact stress of the secondary impact tooth surface increases from the gear top to the gear root. According to the impact stresses of the secondary impact, the dangerous areas of the driven wheel appear near the gear root of the primary and secondary impact tooth surface for the secondary impact of the gear root impact. But during the entire meshing impact, the impact stress of the secondary impact is much less than the impact stress of the primary impact. That is because of the energy loss during the impact and the change of contact area. And the change of the contact area will be discussed later.

In summary, the dangerous areas of the driven wheel still are the gear top of the primary impact tooth surface and the gear root of the secondary impact tooth surface.

\subsection{Impact Stress Distribution on Tooth Surface of Gear Top} Impact. Figure 12 is the impact stresses distribution law of gear top, pitch circle, and gear root while the impact occurs at the gear top (namely, the driving wheel hits the driven wheel at a certain speed while the CATT cylindrical gears' driving gear top and the driven gear root are in contact. During the rebound process, the driving gear root hits the driven gear top the velocity difference $\Delta v$ is also equal to $20 \mathrm{rad} /(\mathrm{s}))$. I is the impact stress of the primary impact tooth surface; II is the impact stress of the secondary impact tooth surface. The first crest of the impact stress is caused by the primary impact; the second crest of the impact stress is caused by the secondary impact.

According to Figure 12, for the primary impact, the gear top, pitch circle, and gear root maximum impact stresses of the primary impact tooth surface are equal to $15.20 \mathrm{MPa}$, 79.30 $\mathrm{MPa}$, and 107.05 $\mathrm{MPa}$, respectively. It indicates that the impact stress of the primary impact tooth surface increases from the gear top to the gear root. Moreover, the gear 

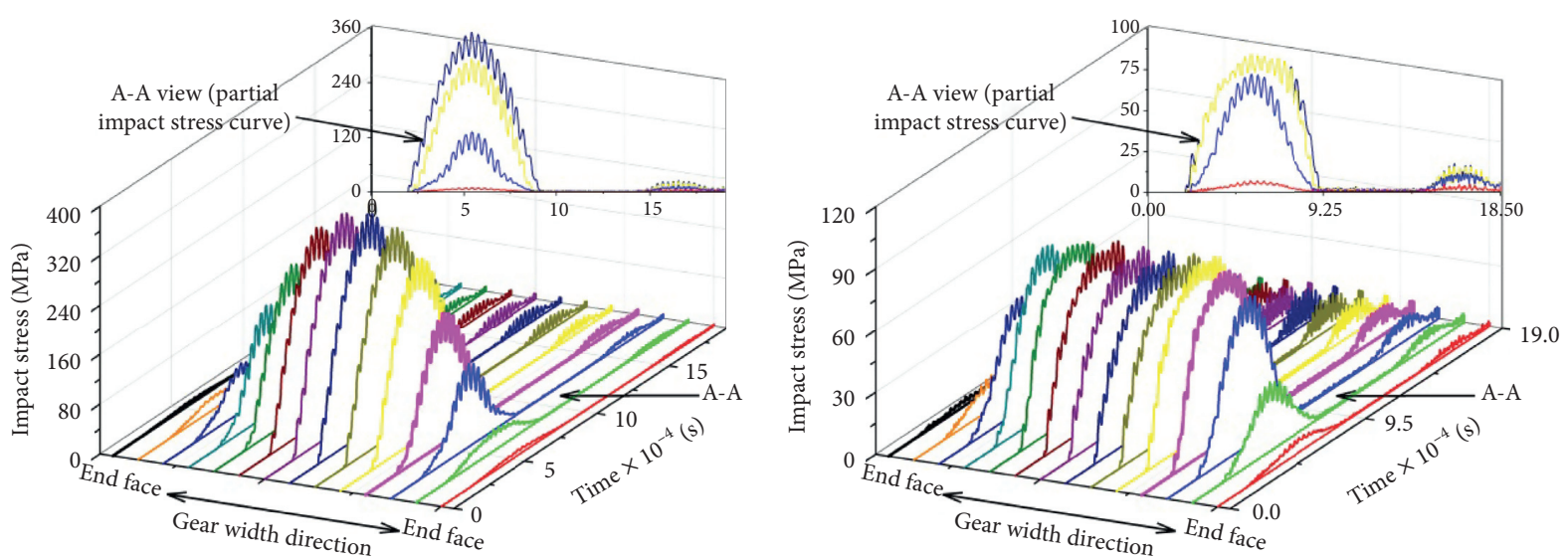

(a)
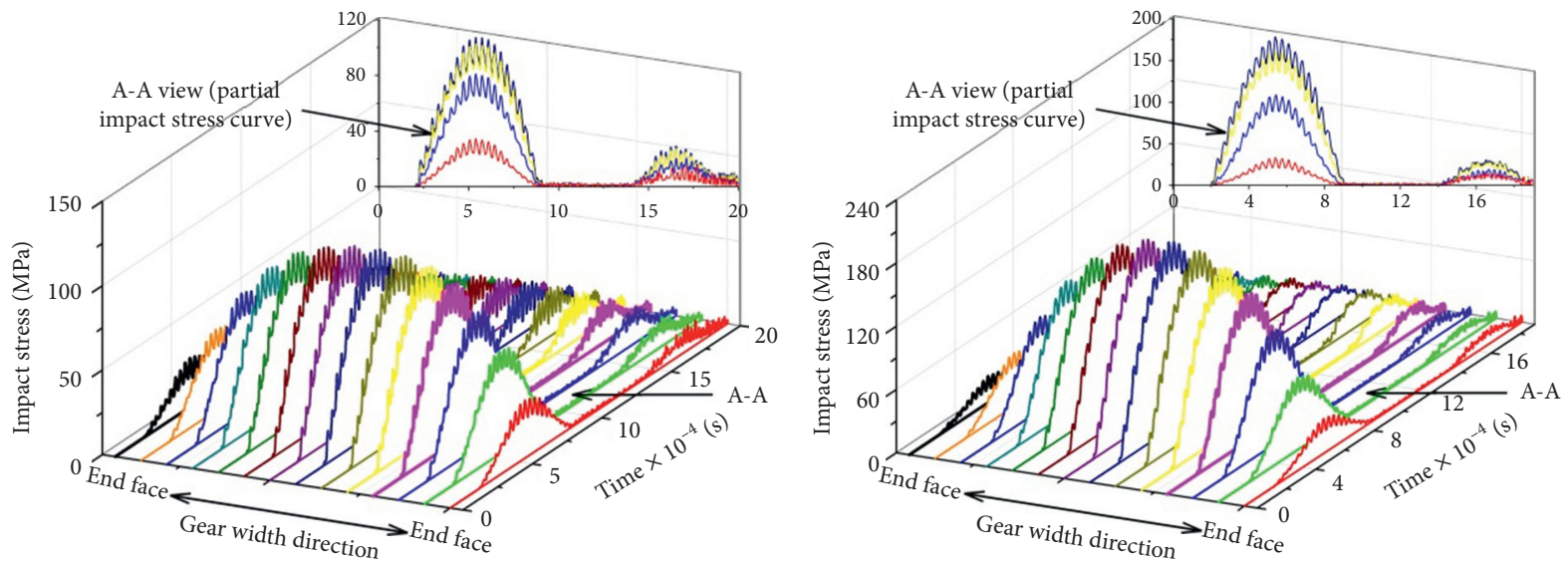

(b)
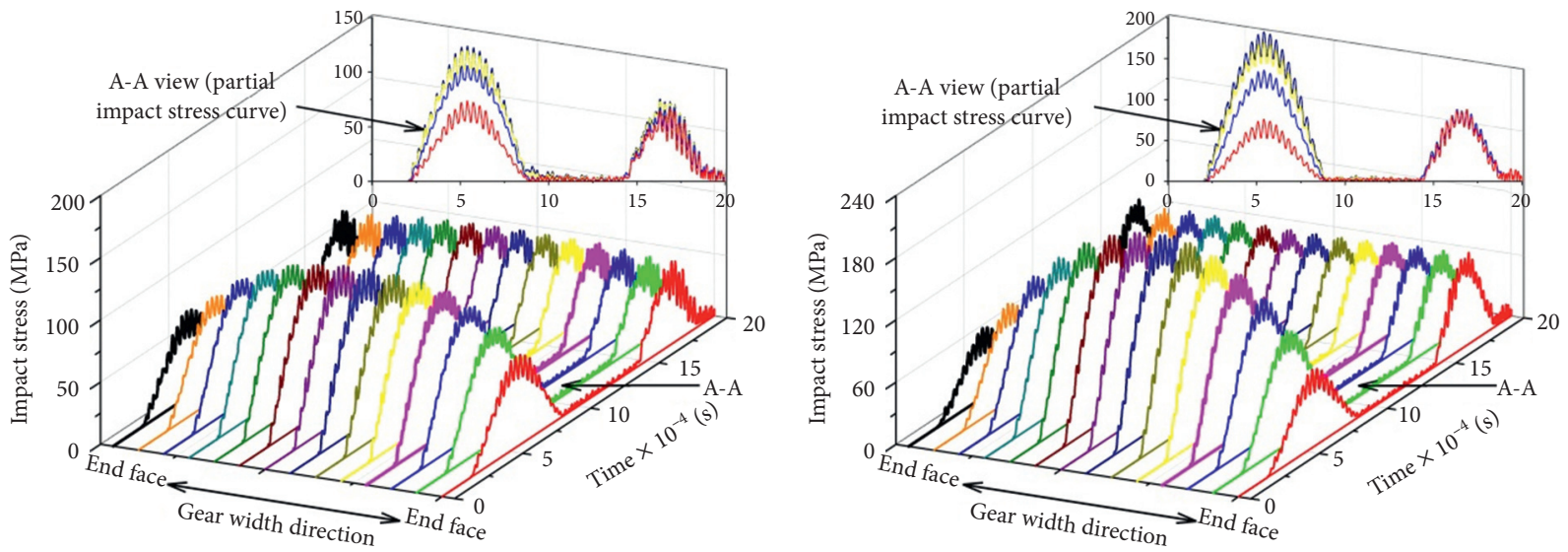

(c)

FIGURE 11: Impact stress of gear top, pitch circle, and gear root while the impact occurs at the gear root. (a) Impact stress of gear top (Iprimary impact tooth surface; II-secondary impact tooth surface). (b) Impact stress of pitch circle (I-primary impact tooth surface; IIsecondary impact tooth surface). (c) Impact stress of gear root (I-primary impact tooth surface; II-secondary impact tooth surface).

top, pitch circle, and gear root maximum impact stresses of the secondary impact tooth surface are equal to $24.52 \mathrm{MPa}$, 37.40 $\mathrm{MPa}$, and $71.38 \mathrm{MPa}$, respectively. The impact stress change trend of the secondary impact tooth surface is the same as the impact stress change trend of the primary impact tooth surface. According to the impact stresses of the primary impact, the dangerous areas of the driven wheel appear near the gear root of the primary and secondary impact tooth surface for the primary impact of the gear top impact.

For the secondary impact of the gear top impact, that is to say, the driving gear root hits the driven gear top. When the defect data of the end face is not considered, the gear top, pitch circle, and gear root maximum impact stresses of the primary impact tooth surface are equal to $52.02 \mathrm{MPa}$, 

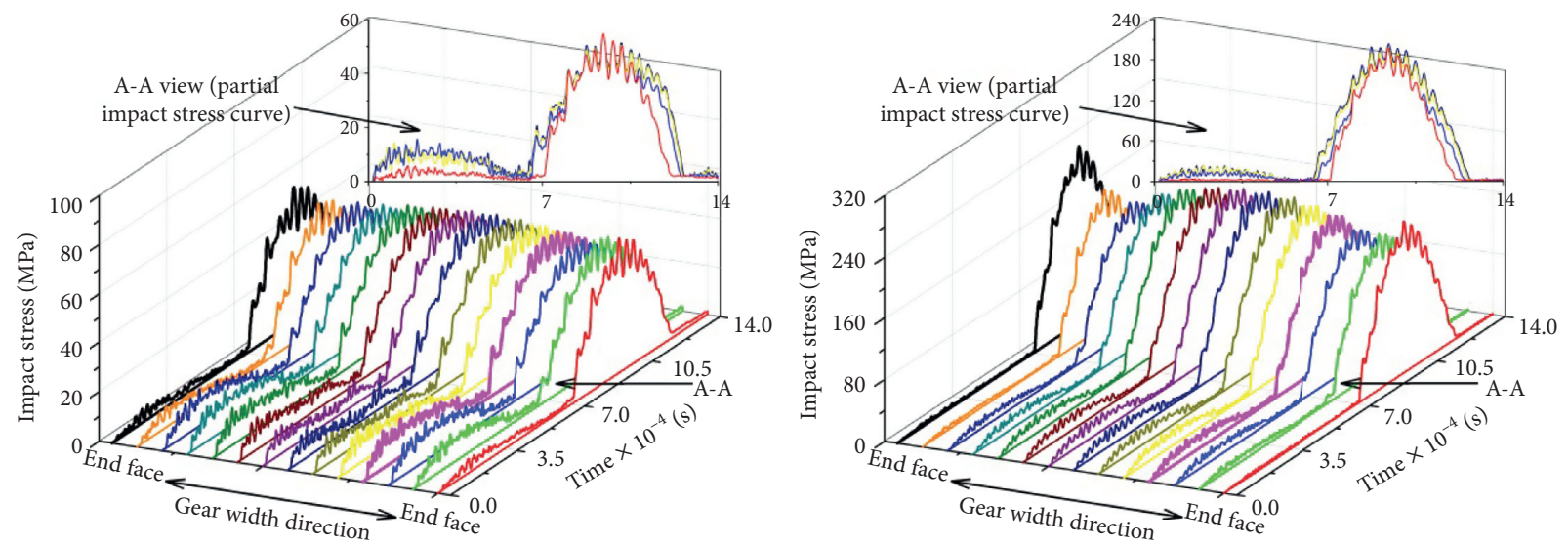

(a)
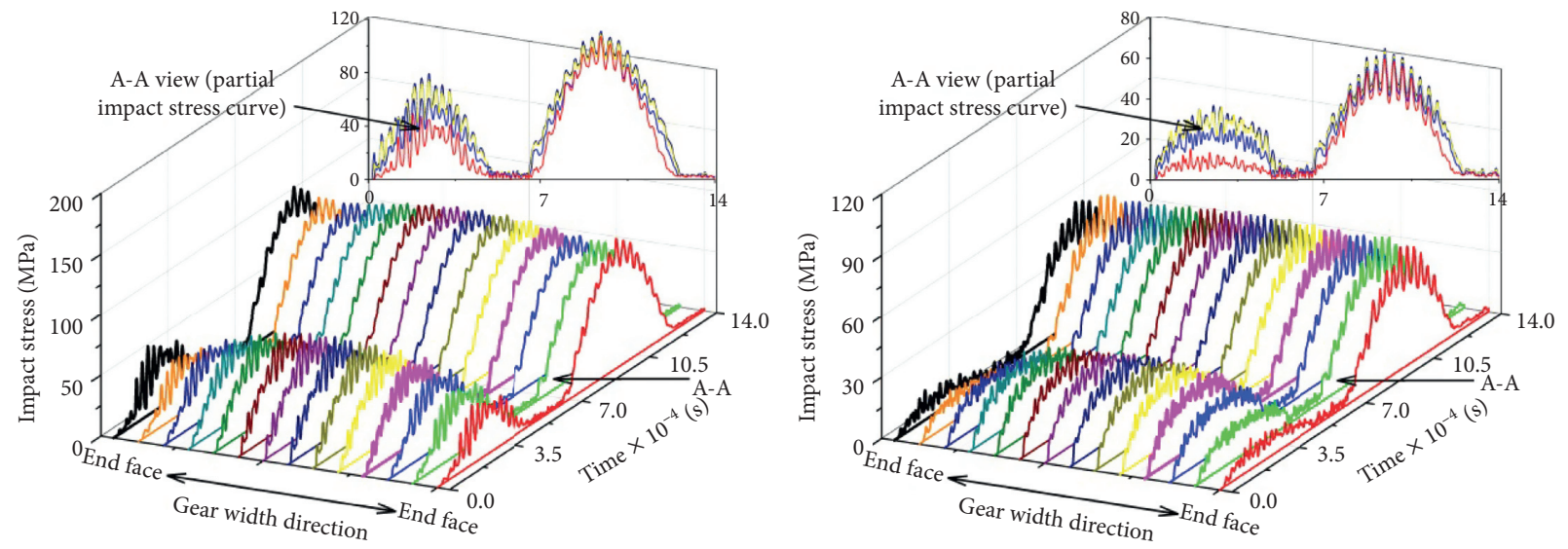

(b)
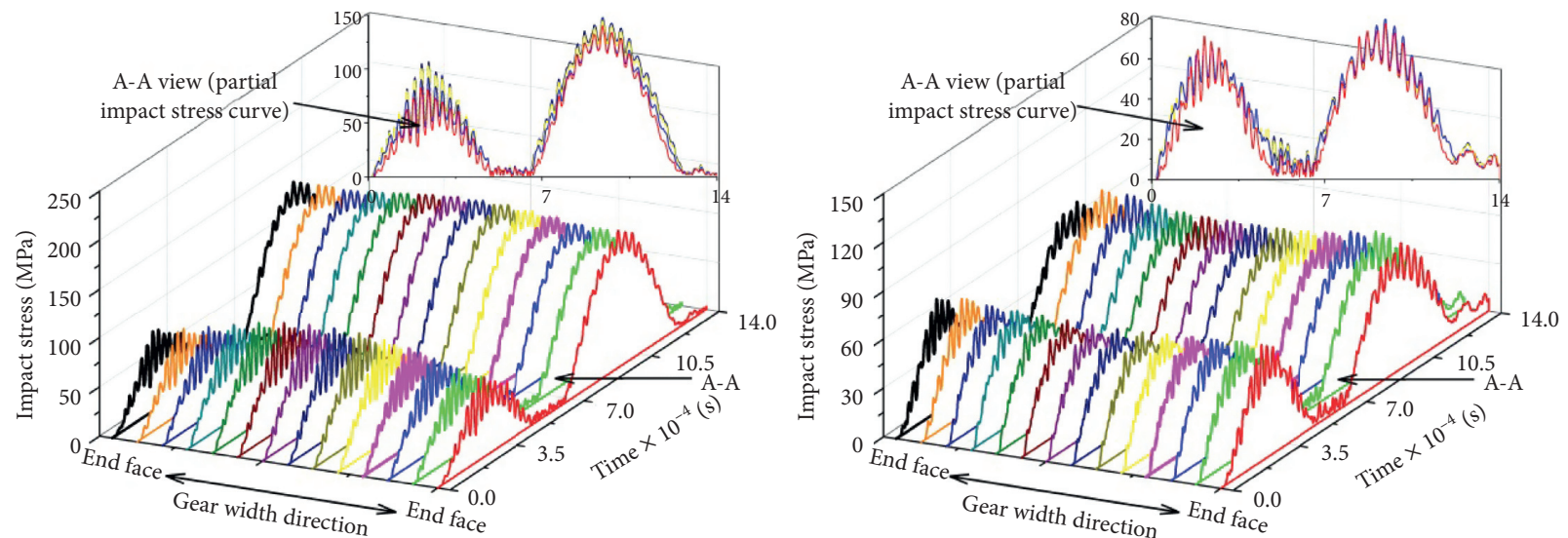

(c)

Figure 12: Impact stress of gear top, pitch circle, and gear root while the impact occur at the gear top. (a) Impact stress of gear top (I-primary impact tooth surface; II-secondary impact tooth surface). (b) Impact stress of pitch circle (I-primary impact tooth surface; II-secondary impact tooth surface). (c) Impact stress of gear root (I-primary impact tooth surface; II-secondary impact tooth surface).

111.02 $\mathrm{MPa}$, and $148.04 \mathrm{MPa}$, respectively. It indicates that the impact stress of the primary impact tooth surface increases from the gear top to the gear root. Moreover, the gear top, pitch circle, and gear root maximum impact stresses of the secondary impact tooth surface are equal to $203.05 \mathrm{MPa}$, 65.67 $\mathrm{MPa}$, and $80.33 \mathrm{MPa}$, respectively. It indicates that the impact stress of the secondary impact tooth surface decreases first and then increases from the gear top to the gear root. The maximum impact stress appears at the gear top of the secondary impact tooth surface due to the gear top of the secondary impact tooth surface is the meshing contact section. According to the impact stresses of the secondary impact, the dangerous areas of the driven wheel appear near at the gear root of the primary impact tooth surface and gear 
top of the secondary impact tooth surface for the secondary impact of the gear top impact.

On the direction of the gear width, when the defect data of the end face is not considered, whether it is the primary impact tooth surface or the secondary impact tooth surface, the maximum impact stresses of the gear top, pitch circle, and gear root appear at the middle of gear width.

In summary, during the entire meshing impact, the dangerous areas of the driven wheel still are the gear root of the primary impact tooth surface and gear top of the secondary impact tooth surface.

\subsection{Impact Stress Distribution on Tooth Surface of Pitch Circle} Impact. Figure 13 is the impact stresses distribution law of gear top, pitch circle, and gear root while the impact occurs at the gear pitch circle (namely, the driving wheel hits the driven wheel at a certain speed while the CATT cylindrical gears' driving gear pitch circle and the driven gear pitch circle are in contact. During the rebound process, the driving gear pitch circle hits the driven gear pitch circle, and the velocity difference $\Delta v$ is also equal to $20 \mathrm{rad} /(\mathrm{s}))$. I is the impact stress of the primary impact tooth surface, II is the impact stress of the secondary impact tooth surface. The first crest of the impact stress is caused by the primary impact; the second crest of the impact stress is caused by the secondary impact.

According to Figure 13, for the primary impact, the gear top, pitch circle, and gear root maximum impact stresses of the primary impact tooth surface are equal to $18.52 \mathrm{MPa}$, 79.44 $\mathrm{MPa}$, and 108.64 $\mathrm{MPa}$, respectively. The gear top, pitch circle, and gear root maximum impact stresses of the secondary impact tooth surface are equal to $23.32 \mathrm{MPa}$, 79.25 $\mathrm{MPa}$, and $130.69 \mathrm{MPa}$, respectively. It is obvious that the impact stress of the primary and secondary impact tooth surface increases from the gear top to the gear root and the dangerous areas of the driven wheel appear near the gear root of the primary and secondary impact tooth surface, especially the secondary impact tooth surface.

As for the secondary impact of the gear top impact, the gear top, pitch circle, and gear root maximum impact stresses of the primary impact tooth surface are equal to 17.00 $\mathrm{MPa}$, 37.06 $\mathrm{MPa}$, and $119.98 \mathrm{MPa}$, respectively. The gear top, pitch circle, and gear root maximum impact stresses of the secondary impact tooth surface are equal to 13.21 MPa, 128.37 MPa, and $118.72 \mathrm{MPa}$, respectively. From the gear top to the gear root, the impact stress of the primary impact tooth surface increases and the impact stress of the secondary impact tooth surface increases first and then decreases. The dangerous areas of the driven wheel appear near the gear root of the primary impact tooth surface and the pitch circle of the secondary impact tooth surface.

In the direction of the gear width, it is the same as the gear root impact and gear top impact. Whether it is the primary impact tooth surface or the secondary impact tooth surface, the maximum impact stresses of the gear top, pitch circle, and gear root appear at the middle of gear width.

In summary, during the entire meshing impact, the dangerous areas of the driven wheel still are the gear root and pitch circle of the secondary impact tooth surface.

5.4. Discussion on the Maximum Impact Stresses of Primary and Secondary Impact Tooth Surfaces. In Figure 10, it is obvious that the meshing force has a little change, that is because the collision time is extremely short, but it is also obvious that the secondary impact stress of the gear surface is greater than the primary impact stress of the gear surface under some special conditions in Figures 12 and 13, and there is a certain energy loss during the collision. We can speculate that, it is the result of the contact area change. The following is the discussion about the influence of the contact area change on the impact stress.

As for the CATT cylindrical gears, in theory, the contact from the CATT cylindrical gear is point contact. But when the tooth surfaces are loaded, if the contact section is projected onto the tangent plane of the meshing point, the contact section generally appears as an ellipse. And the center of the instantaneous contact ellipse overlaps with the theory contact point. In fact, in the entire process of gear meshing, the contact trace is a series of contact ellipses.

According to the author's previous research results, assuming the contact ellipse equation of the CATT cylindrical gear as follows:

$$
A \xi^{2}+B \eta^{2}= \pm \delta
$$

where $\delta$ is the gear surface's elastic deformation.

The contact ellipse's long axis $a$ and short axis $b$ can be expressed as

$$
\begin{aligned}
a & =\left|\frac{\delta}{A}\right|^{1 / 2}, \\
b & =\left|\frac{\delta}{B}\right|^{1 / 2}, \\
A & =\frac{1}{4}\left[k \sum^{\mathrm{I}}-k \sum^{\mathrm{II}}-\left(g_{\mathrm{I}}^{2}-2 g_{\mathrm{I}} g_{\mathrm{II}} \cos 2 \sigma+g_{\mathrm{II}}^{2}\right)^{1 / 2}\right], \\
B & =\frac{1}{4}\left[k \sum^{\mathrm{I}}-k \sum^{\mathrm{II}}+\left(g_{\mathrm{I}}^{2}-2 g_{\mathrm{I}} g_{\mathrm{II}} \cos 2 \sigma+g_{\mathrm{II}}^{2}\right)^{1 / 2}\right], \\
k_{\Sigma}^{i} & =k_{1}^{i}+k_{2}^{i}(i=\mathrm{I}, \mathrm{II}), \\
g_{i} & =k_{1}^{i}-k_{2}^{i}(i=\mathrm{I}, \mathrm{II}), \\
\cos 2 \alpha^{\mathrm{I}} & =\frac{g_{\mathrm{I}}-g_{\mathrm{II}} \cos 2 \alpha}{\left(g_{\mathrm{I}}^{2}-2 g_{\mathrm{I}} g_{\mathrm{II}} \cos 2 \alpha+g_{\mathrm{II}}^{2}\right)^{1 / 2}},
\end{aligned}
$$



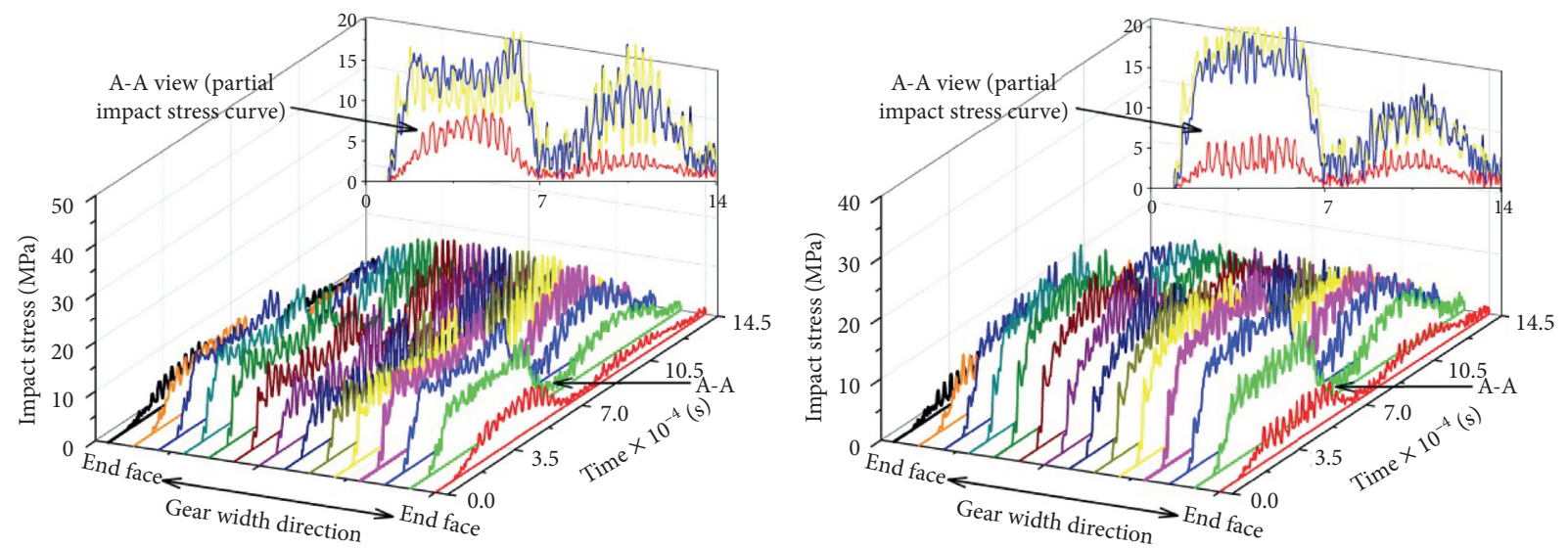

(a)
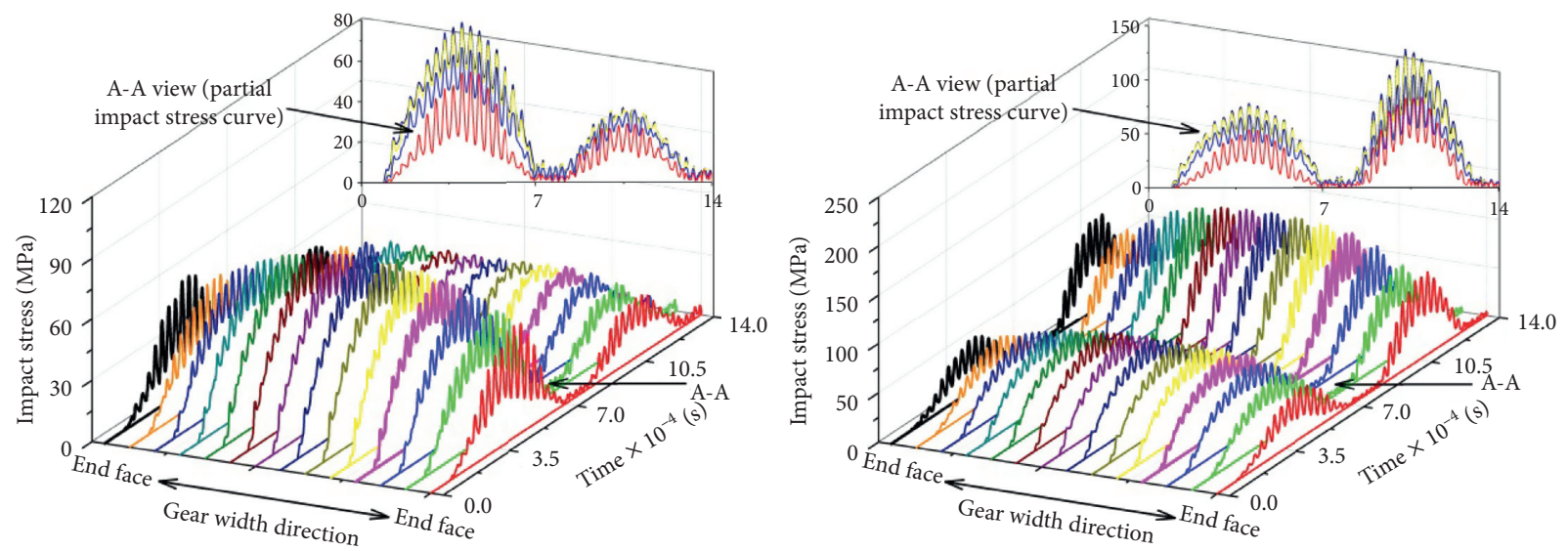

(b)
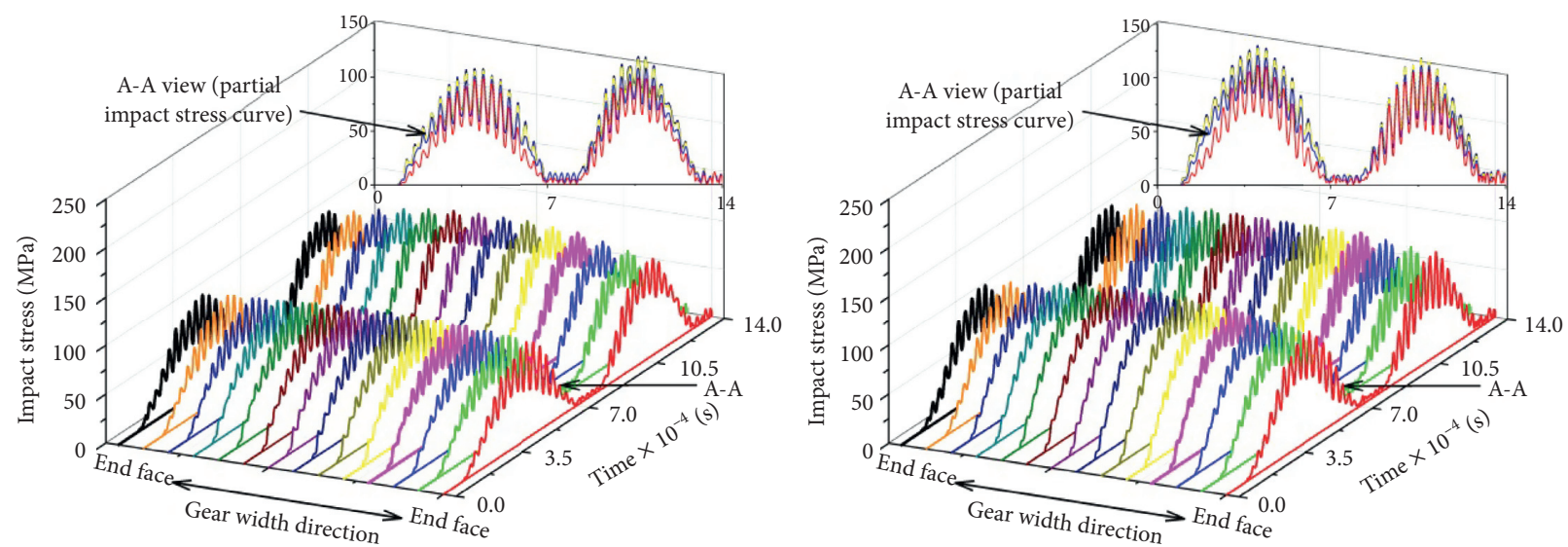

(c)

FIGURE 13: Impact stress of gear top, pitch circle and gear root while the impact occurs at the pitch circle. (a) Impact stress of gear top (Iprimary impact tooth surface; II-secondary impact tooth surface). (b) Impact stress of pitch circle (I-primary impact tooth surface; IIsecondary impact tooth surface). (c) Impact stress of gear root (I-primary impact tooth surface; II-secondary impact tooth surface).

where $k_{1}^{\mathrm{I}}$ and $k_{2}^{\mathrm{I}}$ are the main curvatures of the tooth surface $\Sigma^{\mathrm{I}}, k_{1}^{\mathrm{II}}$, and $k_{2}^{\mathrm{II}}$ are the main curvatures of the tooth surface $\Sigma^{\mathrm{II}}$, and $\sigma$ is the directed angular.

Ellipse area can be represented as

$$
S=\pi a b .
$$

Based on the contact ellipse equation, the contact ellipses at the different meshing points are shown in Figure 14. Figure 14(a) is a contact ellipse on the entire involute surface, and Figure 14(b) is a partial enlarged view near the gear top. The mainly parameters are as follows: $z_{1}=21$, $z_{2}=89 ; m=8 ; R_{T}=500 \mathrm{~mm} ; B=80 \mathrm{~mm}$. The black wire 


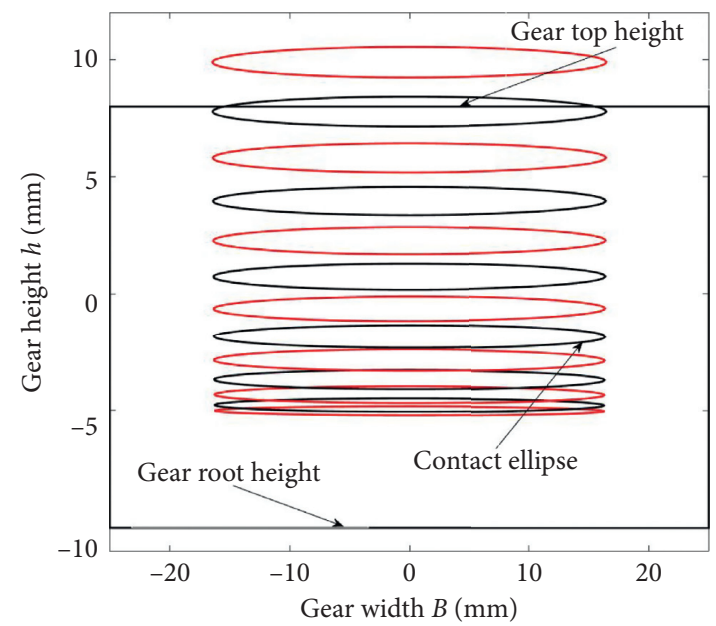

(a)

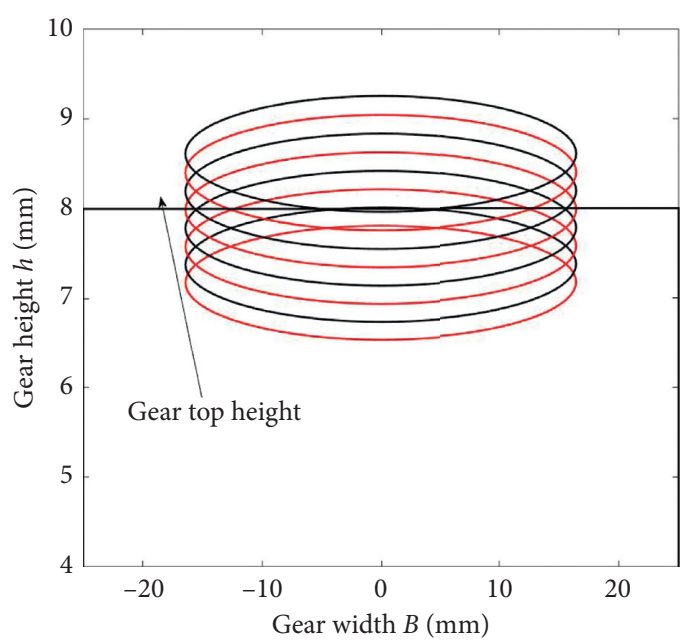

(b)

Figure 14: Contact ellipses at the different meshing points. (a) A contact ellipse on the entire involute surface; (b) a partial enlarged view near the tooth top.

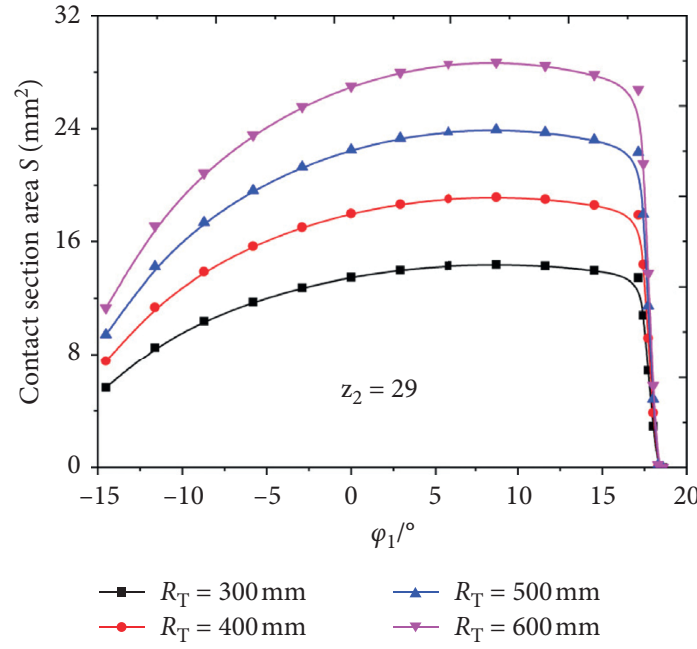

(a)

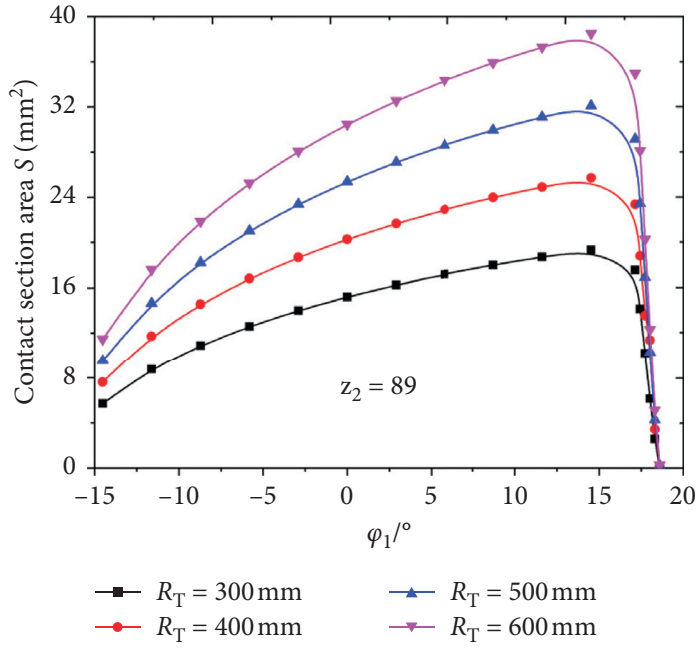

(b)

FIGURE 15: Change trend of the contact ellipse area.

frame rectangle consists of tooth root height, tooth tip height, and tooth end surface; it expresses that tooth surfaces' the real and effective contact section on the involute surface.

From the graphs, it is obvious that the contact section is a series of continuous contact ellipses from the gear root to the gear top during meshing transmission. And it is also obvious that the tooth surfaces' the real and effective contact section are a limited area; the contact ellipse near the gear top will extend beyond this limited area. That is to say, in the real situation, there is no contact in the part of the contact ellipse, namely, the contact section area will decrease gradually.

Figure 15 shows change trend of the contact section area from the gear root to the gear top. The parameters are as follows: $z_{1}=21 ; \quad m=8 ; \quad B=80 \mathrm{~mm} ; z_{2}=29$ and 89 ;
$R_{\mathrm{T}}=300 \mathrm{~mm}, 400 \mathrm{~mm}, 500 \mathrm{~mm}$, and $600 \mathrm{~mm}$, respectively. On the whole, it is obvious that the contact section area gradually increases first and then decreases from the gear root to the gear top regardless of the gear numbers. And it is also obvious that the contact section area decreases in a clifflike manner near the tooth top. It is consistent with the result analysis in Figure 14.

Figure 16 is a $3 \mathrm{D}$ model of CATT cylindrical gear established by simulation processing. Observing the $3 \mathrm{D}$ model, there are many tool traces on the tooth surface. The tool traces are actually contact traces between the driving wheel and the driven wheel. The tool traces of the gear top become short with a cliff-like manner in a limited involute surface, that is to say, the contact area of CATT cylindrical gear rapidly decreases at the gear top. 


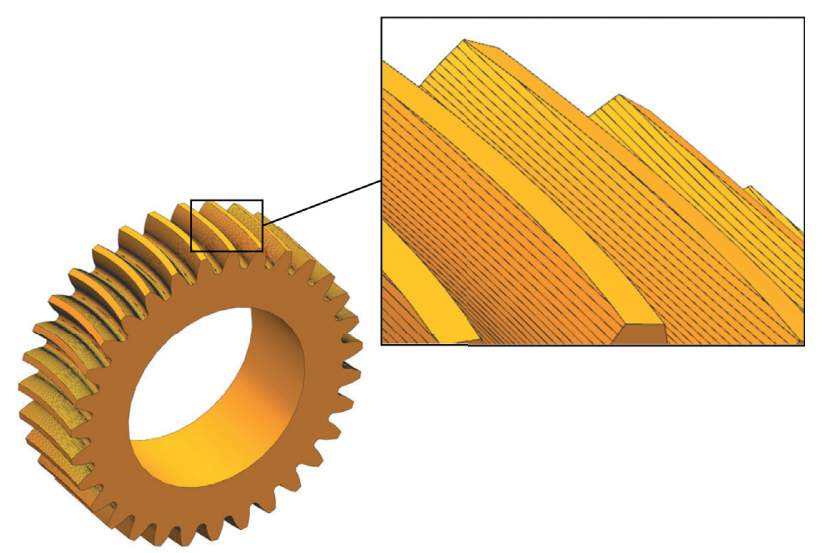

Figure 16: Simulation processing CATT cylindrical gear.

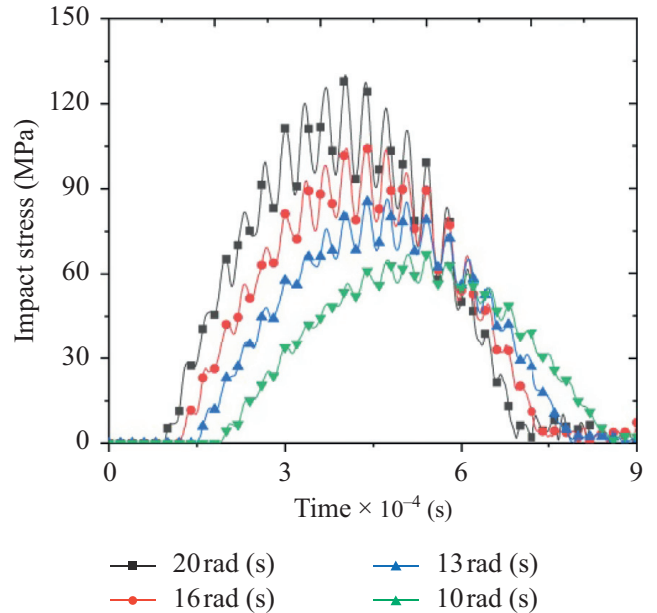

(a)

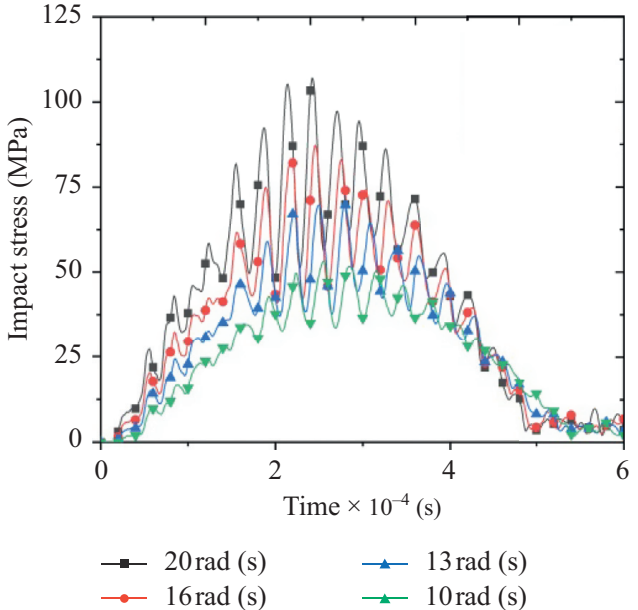

(b)

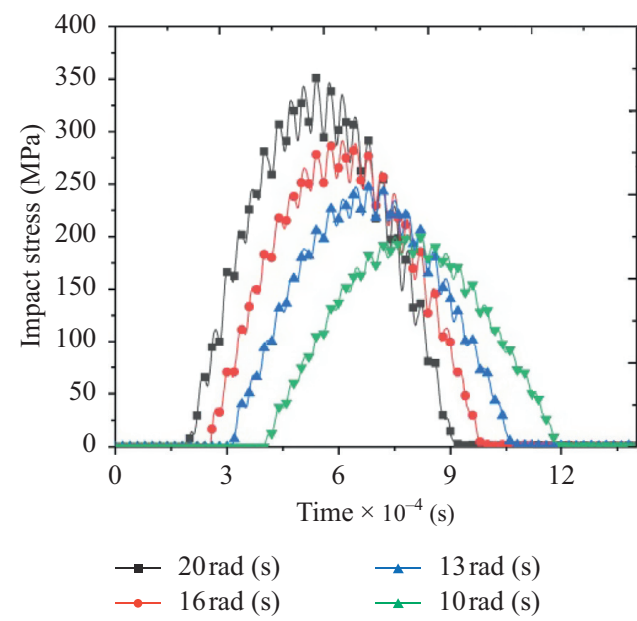

(c)

FIGURE 17: Maximum impact stresses of the primary impact at the different impact: (a) pitch circle impact, (b) gear root impact, and (c) gear top impact. 


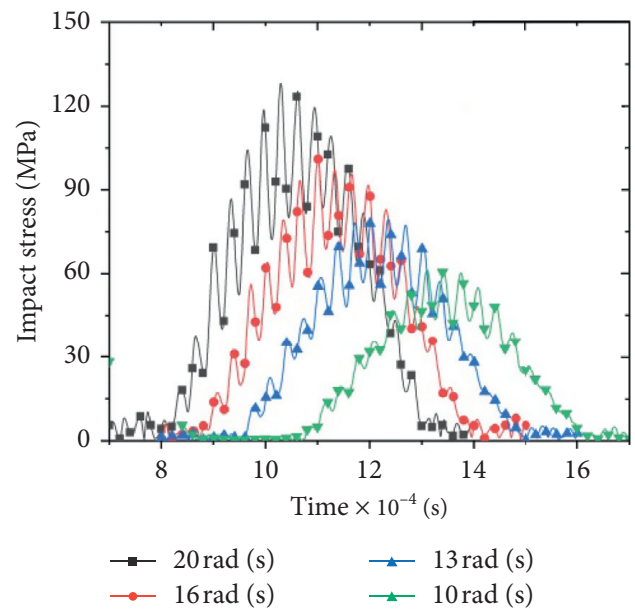

(a)

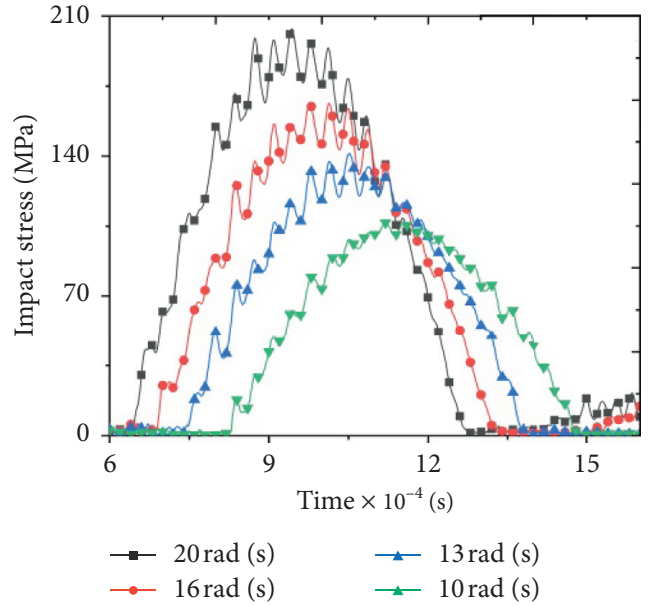

(b)

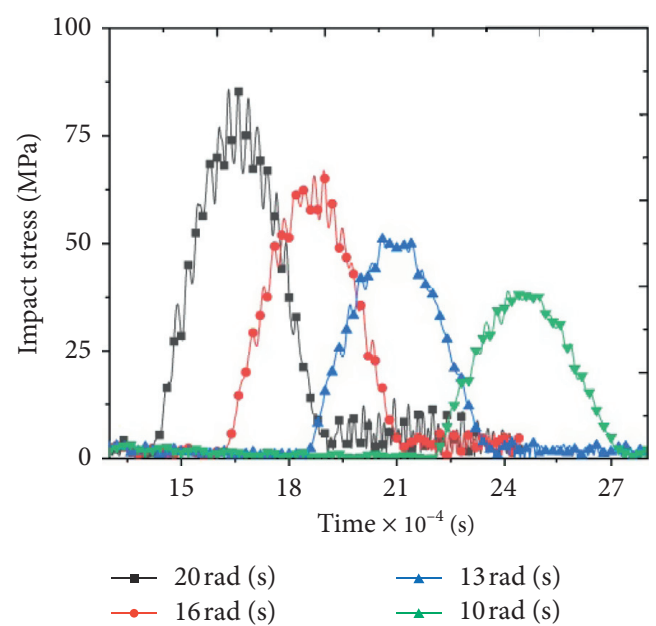

(c)

FIGURE 18: Maximum impact stresses of the secondary impact at the different impact: (a) pitch circle impact, (b) gear root impact, and (c) gear top impact.

In summary, the decreasing of the contact area is the main reason why the secondary impact stress of the gear surface is greater than the primary impact stress of the gear surface under some special conditions in Figures 12 and 13.

\section{Influence of the Impact Speed and Impact Position on the Meshing Contact Impact Stress}

According to the discussion of the impact stress distribution on tooth surface during meshing contact impact, it is obvious that the change of the impact position has an important influence on the maximum impact stress. In gear transmission, the rotation velocity (impact velocity) also plays an important role. It also has an important influence on the maximum impact stress. Figure 17 is the maximum impact stresses time-varying curve of the primary impact at the different impact positions. It is obvious that the maximum impact stresses increase with the increase in impact velocity, and the greater the impact velocity is, the greater the amplification of the maximum impact stress and the greater the fluctuation of the maximum impact stress are. The maximum amplification of the maximum impact stress is the gear top meshing impact, and the minimum is the gear root meshing impact. The maximum fluctuation of the maximum impact stress is the gear top meshing impact, and the minimum is the pitch circle meshing impact. Figure 18 is the maximum impact stresses time-varying curve of the secondary impact at the different impacts. The maximum impact stresses also increase with the increase in impact velocity. The maximum amplification of the maximum impact stress is the gear root meshing impact, and the minimum is the gear top meshing impact. The maximum fluctuation of the maximum impact stress is the pitch circle meshing impact, and the minimum is the gear top meshing impact. Moreover, during the entire meshing impact, the maximum impact stress of the gear top meshing impact is max. To sum up, the impact velocity and impact position have a greater impact on the meshing contact impact, and 
the impact should be avoided as much as possible to ensure the smooth operation of the gear system.

\section{Conclusions}

This paper discusses the meshing contact impact characteristics of circular arc tooth trace cylindrical gear. Firstly, based on the contact dynamics theory and gear transmission physical model, the meshing contact impact hypothesis of the CATT cylindrical gear was put forward. Next, the finite element solution algorithm for solving the impact problem was given. And then, the tooth surface reconstruction was realized, and the $3 \mathrm{D}$ model was established based on the gear tooth surface equation, and the finite element analysis models of the meshing contact impact were established further. Finally, the impact stress distribution on tooth surface during meshing contact impact and influence of the impact speed and impact position on the meshing contact impact stress were investigated. The main conclusions can be expressed as follows:

(1) Aiming at the CATT cylindrical gear transmission problem, the gear meshing contact impact hypothesis was established based on the contact dynamics theory and gear transmission physical model, and the meshing contact impact solution algorithm was given. And a finite element simulation analysis example was used to verify the meshing contact impact hypothesis. It indicated that the meshing contact impact hypothesis is right and finite element analysis is reliable to simulate the impact-collision dynamics problem of the CATT cylindrical gears.

(2) The impact stress distribution on tooth surface during meshing contact impact was discussed. The results show that the driven wheel dangerous areas of gear root impact are the gear top of the primary impact tooth surface and the gear root of the secondary impact tooth surface; the driven wheel dangerous areas of gear top impact are the gear root of the primary impact tooth surface and gear top of secondary impact tooth surface; the driven wheel dangerous areas of pitch circle are the gear root and pitch circle of the secondary impact tooth surface. Moreover, the contact area would change with the change of the meshing contact point from gear root to gear top; it has a major effect on the maximum impact stresses of the gear surface.

(3) Influence of the impact speed and impact position on the meshing contact impact stress was investigated. The results show that the maximum impact stresses increase with the increase in impact velocity, and the greater the impact velocity is, the greater the amplification of the maximum impact stress and the greater the fluctuation of the maximum impact stress are. Moreover, during the entire meshing impact, the maximum impact stress of the gear top meshing impact is max. To sum up, the impact velocity and impact position have a greater impact on the meshing contact impact, and the impact should be avoided as much as possible to ensure the smooth operation of the gear system.

\section{Data Availability}

The data used to support the findings of this study are available from the corresponding author upon request.

\section{Conflicts of Interest}

The authors declare that they have no conflicts of interest.

\section{Acknowledgments}

This project was supported by the Guizhou Province Education Department Young Science and Technology Talents Growth Project (Qianjiaohe KY Zhi [2018] 319 Hao), Zunyi Science and Technology Bureau and the Zunyi Normal University Joint Science and Technology Fund Project (Zunshi Kehe Ji [2018] 13 Hao and Zunshi Kehe HZ Zhi [2020] 10 Hao), the Guizhou Provincial Natural Science Foundation (Qiankehe Platform Talents [2018] 5784-03 Hao), and Zunyi City Innovative Talent Team Project (Zunshike Rencai [2021] 2 Hao).

\section{References}

[1] D. Miler, A. Lončar, D. Žeželj, and Z. Domitran, "Influence of profile shift on the spur gear pair optimization," Mechanism and Machine Theory, vol. 117, no. 6, pp. 189-197, 2017.

[2] V. V. Simon, "Improvements in the mixed elastohydrodynamic lubrication and in the efficiency of hypoid gears," Proceedings of the Institution of Mechanical Engineers Part J Journal of Engineering Tribology, vol. 208-210, pp. 1-16, 2019.

[3] Q. Zhang, L. Hou, R. Tang, and G. Wen, "Method of processing and an analysis of meshing and contact of circular arc tooth trace cylindrical gears," Transactions of FAMENA, vol. 40, no. 4, pp. 11-24, 2016.

[4] Y. Wei, R. Guo, Y. Liu et al., "Analytical calculation of the tooth surface contact stress of cylindrical gear with variable hyperbolic circular-arc-tooth-trace," Symmetry, vol. 12, no. 8, p. 1318, 2020.

[5] Z. Sun, L. Hou, and J. Wang, "Contact strength analysis of circular arc tooth trace cylindrical gear," Journal of the Brazilian Society of Mechanical Sciences and Engineering, vol. 38, no. 3, pp. 999-1005, 2016.

[6] F. L. Litvin, A. M. Egelja, and M. D. Donno, "Computerized determination of singularities and envelopes to families of contact lines on gear tooth surfaces," Computer Methods in Applied Mechanics and Engineering, vol. 158, no. 1-2, pp. 23-24, 1998.

[7] F. L. Litvin and Y. Gutman, "Methods of synthesis and analysis for hypoid gear-drives of "formate" and "helixform"Part 1. Calculations for machine settings for member gear manufacture of the formate and helixform hypoid gears," Journal of Mechanical Design, vol. 103, no. 1, pp. 83-88, 1981.

[8] R. T. Tseng and C. B. Tsay, "Contact characteristics of cylindrical gears with curvilinear shaped teeth," Mechanism and Machine Theory, vol. 39, no. 6, pp. 905-919, 2004.

[9] R. T. Tseng and C. B. Tsay, "Mathematical model and undercutting of cylindrical gears with curvilinear shaped teeth," Mechanism and Machine Theory, vol. 36, no. 11, pp. 189-1202, 2001. 
[10] R. T. Tseng and C. B. Tsay, "Mathematical model and surface deviation of cylindrical gears with curvilinear shaped teeth cut by a hob cutter," ASME Journal of Mechanical Design, vol. 127, no. 5, pp. 271-277, 2005.

[11] F. Zhao, L. Hou, and Y. Duan, "Research on the forming theory analysis and digital model of circular arc gear shaped by rotary cutter," Journal of Sichuan University: Engineering Science Edition, vol. 48, no. 6, pp. 119-125, 2016.

[12] D. Ma, Z. Ye, and H. Yang, "Tooth surface reconstruction and tooth profile geometric analysis of circular arc tooth trace cylindrical gears," Transactions of FAMENA, vol. 43, no. 1, pp. 29-44, 2019.

[13] A. Song, W. Wu, and S. Gao, "The ideal geometry parameters of arch cylindrical gear and its process method," Journal of Shanghai Jiaotong University, vol. 44, no. 12, pp. 1735-1740, 2010.

[14] Q. Chang, L. Hou, and Z. Sun, "Process analysis of two kinds of processing method cylindrical gear with curvilinear shape tooth," Chinese Journal of Mechanical Transmission, vol. 38, no. 6, pp. 96-100, 2014.

[15] Z. Lin, "The continuous curve gear oil pumps," vol. 9, 1995.

[16] D. Ma, Z. Ye, and Y. An, "Design and transmission performance analysis of circular arc tooth trace cylindrical gear reducer," Journal of Mechanical and Electrical Engineering, vol. 37, no. 1, pp. 20-25, 2020.

[17] A. Fuentes-Aznar, R. Ruiz-Orzaez, and I. Gonzalez-Perez, "Comparison of spur, helical and curvilinear gear drives by means of stress and tooth contact analyses," Meccanica, vol. 52, no. 7, pp. 1721-1738, 2017.

[18] A. Fuentes, R. Ruiz-Orzaez, and I. Gonzalez-Perez, "Computerized design, simulation of meshing, and finite element analysis of two types of geometry of curvilinear cylindrical gears," Computer Methods in Applied Mechanics and Engineering, vol. 272, no. 2, pp. 321-339, 2014.

[19] X. Zhang, Y. Xie, and X. Tan, "Design, meshing characteristics and stress analysis of cylindrical gears with curvilinear tooth profile," Transactions of Famena, vol. 40, no. 1, pp. 27-44, 2016.

[20] Y.-C. Chen and C.-C. Lo, "Contact stress and transmission errors under load of a modified curvilinear gear set based on finite element analysis," Proceedings of the Institution of Mechanical Engineers, Part C: Journal of Mechanical Engineering Science, vol. 229, no. 2, pp. 191-204, 2015.

[21] Y. Wei, S. Yang, and Q. Zhang, "Numerical analysis for isothermal elastohydrodynamic lubrication of cylindrical gears with variable hyperbolic circular arc tooth trace," Transactions of FAMENA, vol. 42, no. 1, pp. 61-72, 2018.

[22] Y. Wei, D. Ma, and Y. Liu, "Research on thermal elastohydrodynamic lubrication of cylindrical gears with curvilinear shaped teeth," Journal Chinese Society Mechanical Engineering, vol. 39, pp. 451-458, 2018.

[23] Z. He, T. Zhang, and T. Lin, "Novel mathematical modelling method for meshing impact of helical gear," Mechanism and Machine Theory, vol. 152, Article ID 103949, 2020.

[24] S. Hu, Z. Fang, C. Liu, and L. Xiang, "Measurements and theoretical analysis of a helical gear meshing impact signal," Proceedings of the Institution of Mechanical Engineers, Part K: Journal of Multi-Body Dynamics, vol. 233, no. 4, pp. 827-839, 2019.

[25] F. Guo and Z. Fang, "The statistical analysis of the dynamic performance of a gear system considering random manufacturing errors under different levels of machining precision," Proceedings of the Institution of Mechanical
Engineers, Part K: Journal of Multi-Body Dynamics, vol. 234, no. 1, pp. 3-18, 2020.

[26] R. G. Munro, L. Morrish, and D. Palmer, "Gear transmission error outside the normal path of contact due to corner and top contact," Proceedings of the Institution of Mechanical Engineers, Part C: Journal of Mechanical Engineering Science, vol. 213, no. 4, pp. 389-400, 1999.

[27] A. Bajer and L. Demkowicz, "Dynamic contact impact problems, energy conservation, and planetary gear trains," Computer Methods in Applied Mechanics and Engineering, vol. 191, no. 37-38, pp. 4159-4191, 1999.

[28] Y. Hu, Y. Shao, Z. Chen, and M. J. Zuo, "Transient meshing performance of gears with different modification coefficients and helical angles using explicit dynamic FEA," Mechanical Systems and Signal Processing, vol. 25, no. 5, pp. 1786-1802, 2011.

[29] J. Tang, W. Zhou, and S. Chen, "Contact-impact analysis of gear transmission system," Journal of Mechanical Engineering, vol. 47, no. 7, pp. 22-28, 2011.

[30] J. T. Oden and G. F. Carey, Finite Elements, Prentice-Hall, Upper Saddle River, NJ, USA, 1981.

[31] B. C. Wen, Mechanical Design Handbook, Machine Press, Beijing, China, 2018. 